\title{
DSpace@MIT
}

\author{
MIT Open Access Articles
}

\section{A View of Tropical Cyclones from Above: The Tropical Cyclone Intensity Experiment}

The MIT Faculty has made this article openly available. Please share how this access benefits you. Your story matters.

Citation: Doyle, James D. et al. “A View of Tropical Cyclones from Above: The Tropical Cyclone Intensity Experiment." Bulletin of the American Meteorological Society 98, 10 (October 2017): 2113-2134 (c) 2017 American Meteorological Society

As Published: http://dx.doi.org/10.1175/BAMS-D-16-0055.1

Publisher: American Meteorological Society

Persistent URL: http://hdl.handle.net/1721.1/115060

Version: Final published version: final published article, as it appeared in a journal, conference proceedings, or other formally published context

Terms of Use: Article is made available in accordance with the publisher's policy and may be subject to US copyright law. Please refer to the publisher's site for terms of use. 


\title{
A VIEW OF TROPICAL CYCLONES FROM ABOVE The Tropical Cyclone Intensity Experiment
}

\author{
James D. Doyle, Jonathan R. Moskaitis, Joel W. Feldmeier, Ronald J. Ferek, Mark Beaubien, Michael M. Bell, \\ Daniel L. Ceell, Robert L. Creasey, Patrick Duran, Russell l. Elsberry, William A. Komaromi, John Molinari, \\ David R. Ryglicki, Daniel P. Stern, Christopher S. Velden, Xuguang Wang, Todd Allen, Bradford S. Barrett, \\ Peter G. Black, Jason P. Dunion, Kerry A. Emanuel, Patrick A. Harr, Lee Harrison, Eric A. Hendricks, \\ Derrick Herndon, William Q. Jeffries, Sharanya J. Majumdar, James A. Moore, Zhaoxia Pu, \\ Robert F. Rogers, Elizabeth R. Sanabia, Gregory J. Tripoli, and Da-Lin Zhang
}

\author{
High-resolution observations of Hurricanes Patricia, Joaquin, and Marty in 2015 provide \\ new insight into tropical cyclone structure and intensity change as part of the \\ Tropical Cyclone Intensity field program.
}

A ccurate prediction of tropical cyclone (TC) intensity remains one of the great challenges in atmospheric science today. Previous research programs and field campaigns have focused on processes in the boundary layer, midtroposphere and convection, large-scale environment, and ocean mixed layer, all of which impact TC development and intensification to varying degrees. Several specialized TC field campaigns over the past 15 years have focused on various aspects of these processes, including the Coupled Boundary Layers Air-Sea Transfer (CBLAST; Black et al. 2007) experiment, the Tropical Cloud Systems and Processes (TCSP; Halverson et al. 2007) experiment, the NASA African Monsoon Multidisciplinary Analysis (NASA-AMMA or NAMMA; Zipser et al. 2009), The Observing System Research and Predictability Experiment (THORPEX) Pacific Asian Regional Campaign (T-PARC), and the Office of Naval Research (ONR) Tropical Cyclone Structure 2008 (TCS-08; Elsberry and Harr 2008), as well as the Impact of Typhoons on the Ocean in the Pacific/ Tropical Cyclone Structure 2010 (ITOP/TCS10; D'Asaro et al. 2014) field campaigns. However, the upper-tropospheric TC outflow layer remained largely unexplored until the recent Hurricane and Severe Storm Sentinel (HS3) field campaign of 2012-14 (Braun et al. 2016). It has been hypothesized that this upper-tropospheric layer is a critical one, as changes in the TC outflow can directly cause changes in the TC secondary circulation (e.g., Holland and Merrill 1984; Merrill 1988a; Komaromi and Doyle 2017). During the HS3 field campaign, the TC outflow layer and secondary circulation were only probed at limited horizontal resolution because of instrumentation technology limitations. In the ONR Tropical Cyclone Intensity (TCI) field campaign conducted in 2015, new dropsonde technology allowed for unprecedented high-fidelity observations of the outflow layer and inner-core structure of three prominent TCs.

The importance of the TC outflow layer in affecting both storm motion (Flatau and Stevens 1993) and structure (Holland and Merrill 1984) has been known for some time. Past observational studies have documented that intensifying TCs have outflow that links to synoptic-scale upper-tropospheric flow features, while nonintensifying TCs have no such 
link (Merrill 1988a). Recent research has further demonstrated that outflow tends to develop in regions where upper-tropospheric inertial stability is low, and stronger outflow tends to be associated with intensifying TCs (Rappin et al. 2011; Barrett et al. 2016; Komaromi and Doyle 2017). Synoptic-scale forcing has been found to further reduce upper-tropospheric inertial stability, which favors intensification (Rappin et al. 2011). Additionally, eddy flux convergence of absolute angular momentum in the upper troposphere from midlatitude troughs can influence the outflow-layer structure and TC intensity changes in these low-inertial-stability regions (Merrill 1988b; Molinari and Vollaro 1989). The induced secondary circulation associated with upper-tropospheric TC outflow varies, depending on the outflow-layer characteristics. Of special importance is the azimuthal asymmetry of the outflow layer, commonly seen in the form of outflow jet streaks emanating preferentially from different quadrants of the TC depending on the nature of the TC's environment. Jet streak dynamics play a crucial role in extratropical storm development (e.g., Uccellini 1990) and may have a similar role in TC intensity change.

The overarching goal of the TCI program is to improve the prediction of TC intensity change, especially rapid intensification (RI) and rapid decay (RD), as well as TC structural changes that are hypothesized to occur through synergistic interaction with outflow. New observational and modeling research is required to elucidate the connections between the outflow and inflow-ascent branches of the secondary circulation and how they vary as a function of the vortex characteristics and TC environmental characteristics in realistic scenarios. During the TCI field campaign in 2015, the outflow layer and inner core of several TCs were observed by dropsondes at much higher resolution than in any other previous experiment. We have identified several key science goals for the TCI program to be addressed using the observational dataset collected during the field campaign:

- understand the coupling of TC outflow with innercore convection and its implications for intensity change;

- interpret observations of the finescale horizontal and vertical structure of the outflow layer and inner-core regions of the TC;

- assess the quantitative impact of assimilating observations in the TC inner core and outflow layer on model forecasts of TC track and intensity; and - quantify the predictability of TC intensity change and its relationship to outflow layer changes using ensembles and adjoint-based modeling systems.

The purpose of this paper is to present an overview of the TCI field campaign and to provide some early scientific highlights. None of these preliminary science results are sufficient to fully address any of the stated objectives above. However, this overview does demonstrate the considerable promise of the new observing technology applied during the TCI field campaign. The following section describes the WB-57 aircraft and the TCI instrument payload, followed by an overview of the TCI field campaign and highlights of some of the results from TCI. The final section gives a summary and concluding remarks.
AFFILIATIONS: DOYLE, MOSKAITIS, KOMAROMI AND RYGLICKI-Naval Research Laboratory, Monterey, California; FeLdMEIER AND FEREK-Office of Naval Research, Arlington, Virginia; Beaubien, Allen, AND JefrRIESYankee Environmental Systems, Inc., Turners Falls, Massachusetts; BELL-Colorado State University, Fort Collins, Colorado; CECILNASA Marshall Space Flight Center, Huntsville, Alabama; CREASEY, HarR, ANd Hendricks-Naval Postgraduate School, Monterey, California; Duran, Harrison, AND MolinarI-University at Albany, State University of New York, Albany, New York; ELSBERRY — University of Colorado Colorado Springs, Colorado Springs, Colorado; STERN-University Corporation for Atmospheric Research, Monterey, California; Velden and HeRndon-Cooperative Institute for Meteorological Satellite Studies, University of Wisconsin-Madison, Madison, Wisconsin; WANG - University of Oklahoma, Norman, Oklahoma; BARRETT AND SANABIA-U.S. Naval Academy, Annapolis, Maryland; BLACK*_SAIC, Monterey, California; DuNION — NOAA/Atlantic Oceanographic and Meteorological Laboratory/ Hurricane Research Division, Cooperative Institute for Marine and Atmospheric Studies, Rosenstiel School of Marine and Atmospheric Science, University of Miami, Miami,
Florida; EMANUEL-Massachusetts Institute of Technology, Cambridge, Massachusetts; Majumdar-University of Miami, Miami, Florida; Moore-NCAR, Boulder, Colorado; Pu—University of Utah, Salt Lake City, Utah; Rogers_-NOAA/Atlantic Oceanographic and Meteorological Laboratory/Hurricane Research Division, Miami, Florida; TRIPOLI-University of Wisconsin-Madison, Madison, Wisconsin; ZhANG - University of Maryland, College Park, College Park, Maryland *CURRENT AFFILIATION: BLACK—Cherokee Nation Strategic Programs, LLC, Salinas, California CORRESPONDING AUTHOR: James D. Doyle,

james.doyle@nrlmry.navy.mil

The abstract for this article can be found in this issue, following the table of contents.

DOI:I0.II75/BAMS-D-I6-0055.I

In final form 13 March 2017

(C)2017 American Meteorological Society

For information regarding reuse of this content and general copyright information, consult the AMS Copyright Policy. 
WB-57 AIRCRAFT AND TCI INSTRUMENT

PAYLOAD. The TCI field campaign utilized the NASA Johnson Space Center at Ellington Field WB-57 research aircraft. The typical maximum flight duration is $\sim 6 \mathrm{~h}$, and with an aircraft true airspeed of 380-400 knots $\left(1 \mathrm{kt}=0.51 \mathrm{~m} \mathrm{~s}^{-1}\right)$, this implies a maximum flight distance of $\sim 2,200$ nautical miles $(\sim 4,100 \mathrm{~km})$. The WB-57 has a cruising altitude of approximately $18 \mathrm{~km}$ or $60,000 \mathrm{ft}$, such that the aircraft flies above the TC and its outflow layer, providing an opportunity to sample from the top of the TC to the ocean surface. For the TCI field campaign, the WB-57 was equipped with two instruments: the High-Definition Sounding System (HDSS) and the Hurricane Imaging Radiometer (HIRAD).

HDSS and XDD. The HDSS and Expendable Digital Dropsonde (XDD) technology (Black et al. 2017) provide a unique capability to sample a TC with a "burst" of dropsondes deployed over a small time window. For example, the highest sampling rate achieved during a TCI science flight was a sequence of 46 dropsondes released at 20 -s intervals. Sampling using HDSS can capture strong gradients associated with outflow jet features and inner-core structures that have not been straightforward to sample in the past.

The HDSS is an integrated system of antennas, receivers, and telemetry that receive data from XDDs, which are then telemetered to the ground via satellite. The measurements include GPS-based location, altitude, horizontal wind velocity, and dropsonde fall speed at $4 \mathrm{~Hz}$; pressure, temperature, and humidity at $2 \mathrm{~Hz}$; and skin sea surface temperature (SST) at $1 \mathrm{~Hz}$. The instruments to measure pressure, temperature, and humidity are a pressure transducer, a fastresponse thermistor with digital oversampling, and a relatively slow-response hygrometer, respectively. The skin SST is measured with an infrared microradiometer at $8-12-\mu \mathrm{m}$ wavelengths. The physical layout of the XDD printed circuit board (PCB) and sheath are shown in Fig. 1a. The XDD does not use a parachute or drogue. Instead, etched grooves in the polystyrene foam PCB housing provide air pathways between the foam and the cardboard sheath to maintain a stable descent. The XDD sea level descent rate is approximately $18 \mathrm{~m} \mathrm{~s}^{-1}$, as compared to $10-12 \mathrm{~m} \mathrm{~s}^{-1}$ for the Vaisala RD-94 sondes used on the NOAA WP-3D and Air Force WC-130J aircraft (Stern et al. 2016). The HDSS features two cameras to record dropsonde ejection.

The HDSS has been evaluated and validated successfully in a series of test flights on the following platforms (Black et al. 2017):
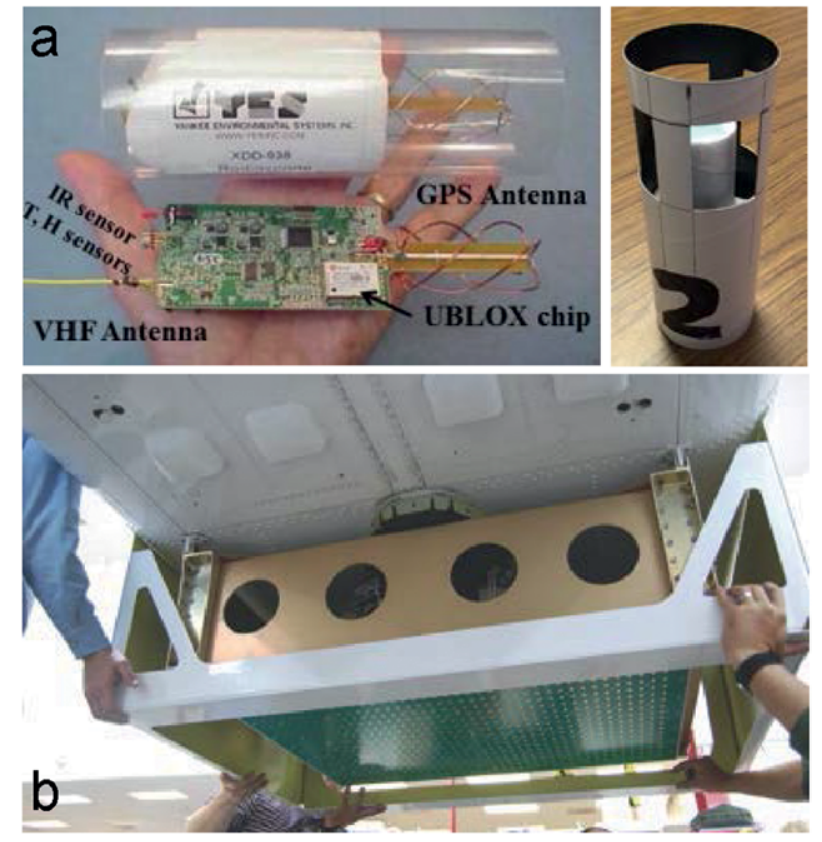

FIG. I. (a) HDSS XDD (from Black et al. 2017), with (left) the printed circuit board layout and (right) the sheath. (b) HIRAD system being mounted on an aircraft.

- Naval Postgraduate School (NPS), Center for Interdisciplinary Remotely-Piloted Aircraft Studies (CIRPAS) Twin Otter aircraft,

- NASA Wallops Flight Facility (WFF) WP-3D aircraft,

- NASA Armstrong Flight Research Center (AFRC) DC-8, and

- NASA Johnson Space Center-Ellington Field WB-57 aircraft.

TCI is the first program in which HDSS was deployed in the field for science missions.

HIRAD. The HIRAD is a four-channel, C-band, synthetic thinned array radiometer (see Fig. 1b) designed to measure a swath of ocean surface wind speeds in hurricanes. It has been flown on high-altitude aircraft (NASA Global Hawk and WB-57) in order to map a $\sim 50-\mathrm{km}$-wide swath from individual flight legs across hurricanes. Before the 2015 TCI field campaign, HIRAD overflew Hurricanes Earl and Karl in 2010, Hurricane Ingrid and Tropical Storm Gabrielle in 2013, and Hurricane Gonzalo in 2014.

Wind speed retrievals from HIRAD (Cecil and Biswas 2017) take advantage of the fact that the C-band emissivity of the ocean surface increases with increasing surface wind speed, due to increased foam coverage. The four C-band channels also have 
varying sensitivity to rain, so rain and wind speed can be retrieved simultaneously. This concept is similar to that employed by the operational Stepped Frequency Microwave Radiometer (SFMR; Uhlhorn et al. 2007), which retrieves nadir traces of wind speed and rain rate from low-altitude aircraft.

TCI FIELD CAMPAIGN OVERVIEW. Field campaign concept of operations. The TCI field campaign operated in an "on demand" fashion, mobilizing the aircraft and personnel when a promising opportunity to observe a TC was identified by the mission science team. This concept of operations was facilitated by the flexibility in basing options for the WB-57. The aircraft's home base was Ellington Field in Houston, Texas, which is well-positioned for a flight over a TC in the Gulf of Mexico. However, the aircraft also could be forward deployed to a wide range of locations in the continental United States, as well as to St. Croix and Bermuda. Thus, most TCs in the Atlantic basin and TCs in the eastern North Pacific basin near the western coast of Mexico were potentially accessible by the WB-57 for observation. Ultimately, all TCI science flights took place from two forward-operating locations: 1) Harlingen, Texas, and 2) Warner Robbins, Georgia.

The forward-deployment process began at least 3 days before the first science flight departed from the forward-operating base (timeline dependent on the forward-deployment location), in order to move the aircraft, aircraft support equipment, aircraft personnel, instrument personnel, and a mission science representative to the forward-operating base. Daily planning teleconferences among the mission scientists and forecasters were held to review the latest model forecasts and make aircraft deployment decisions. Such meetings were held from late July through late October, covering as much of the hurricane season as feasible to maximize observational opportunities.

Science flight planning and management. Once a forward-deployment decision was made, the flightplanning process began. Mission scientists worked collaboratively to develop a planned series of flighttrack waypoints and dropsonde release locations, which were provided to the pilots for review on the day before the intended science flight. After takeoff, the science flight was managed remotely by a team of mission scientists in Monterey, California. This team was responsible for updating the flight-track waypoints and dropsonde release locations to guide the plane over the TC center during center-crossing flight legs. The updated waypoints and dropsonde release locations were communicated to the forward-deployed mission scientist representative, who passed this information to the pilots and instrument operators.

Collaborative observing programs. Several of the storms observed by TCI, particularly Hurricane Patricia and Hurricane Joaquin, were also sampled by airborne in situ and remote sensing instruments associated with observing programs other than TCI, including the U.S. Air Force (USAF) 53rd Weather Reconnaissance Squadron WC-130J tasked by the National Hurricane Center (NHC), the NOAA Intensity Forecasting Experiment (IFEX; Rogers et al. 2006, 2013), and the U.S. Naval Academy's Training and Research in Oceanic and Atmospheric Processes in Tropical Cyclones (TROPIC) program (Sanabia et al. 2013). The IFEX measurements taken from the low-level (1.5-4-km flight level), storm-penetrating WP-3D aircraft included dropsonde kinematic and thermodynamic profiles (Hock and Franklin 1999) and $\mathrm{X}$-band tail Doppler radar measurements of kinematic and precipitation structure. The combination of high-density, high-altitude dropsonde measurements and wide-swath surface wind speed measurements from the WB-57, along with the Doppler radar measurements from the WP-3D provided a unique depiction of Patricia's structure (Rogers et al. 2017). During the IFEX flights, the WP-3D aircraft also featured a C-band lower-fuselage radar that provided reflectivity, flight-level instruments, and the SFMR.

For Joaquin, subsurface ocean observations were obtained through deployment of Airborne Expendable Bathythermographs (AXBTs) and Air Launched Autonomous Micro Observer (ALAMO) profiling floats as part of the TROPIC field program. Sixtythree AXBTs and six ALAMO floats were deployed during four USAF 53rd Weather Reconnaissance Squadron WC-130J missions that took place 2-5 October 2015. These observations provide an excellent opportunity to examine the vertical temperature profile of the upper ocean beneath a hurricane, in conjunction with the HIRAD surface wind field observations and dropsonde observations from TCI.

Summary of TCl science flights. A total of $11 \mathrm{TCI}$ science flights were performed, investigating four different storms, as shown in Table 1. There was one flight over the remnants of Tropical Storm Erika, two flights over Hurricane Marty, and four flights each over Hurricane Joaquin and Hurricane Patricia. Following the experiment, the HDSS dropsonde and HIRAD observations went through a rigorous qualitycontrol process. The dropsonde observations were 


\begin{tabular}{|c|c|c|c|c|}
\hline Storm & Basin & Date & Dropsonde launch times & Number of dropsondes \\
\hline Erika remnants & Atlantic & 30 Aug & I522-1813 UTC & 59 \\
\hline Marty & Eastern North Pacific & 27 Sep & 20I8-2I28 UTC & 57 \\
\hline Marty & Eastern North Pacific & $28 \mathrm{Sep}$ & I827-20| 8 UTC & 84 \\
\hline Joaquin & Atlantic & $2 \mathrm{Oct}$ & I550-1940 UTC & 84 \\
\hline Joaquin & Atlantic & $3 \mathrm{Oct}$ & |537-200| UTC & 78 \\
\hline Joaquin & Atlantic & $4 \mathrm{Oct}$ & I62I-1932 UTC & 84 \\
\hline Joaquin & Atlantic & $5 \mathrm{Oct}$ & I552-1904 UTC & 83 \\
\hline Patricia & Eastern North Pacific & 20 Oct & |954-2|26 UTC & 13 \\
\hline Patricia & Eastern North Pacific & 21 Oct & I855-2040 UTC & 77 \\
\hline Patricia & Eastern North Pacific & 22 Oct & I746-1945 UTC & 83 \\
\hline Patricia & Eastern North Pacific & $23 \mathrm{Oct}$ & 1956-2|54 UTC & 84 \\
\hline
\end{tabular}

quality controlled using the Atmospheric Sounding Processing Environment (ASPEN) software package along with a subsequent manual evaluation by a team of TCI scientists, with each data point being reviewed by at least two scientists (Bell et al. 2016). For HIRAD, optimal combinations of frequency subbands and antenna elements were identified, and the most reliable portions of the HIRAD data were given the most weight during generation of products. Further descriptions of the science flights for Marty, Joaquin, and Patricia are provided in the following section, together with observational highlights demonstrating the unique capabilities of the TCI instrument suite.

HIGHLIGHTS. Hurricane Marty. Marty was a short-lived TC that formed, strengthened to a hurricane, and subsequently dissipated over the waters southwest of Acapulco, Mexico. The NHC best track for Marty is shown in Fig. 2a. The storm was designated a tropical depression by NHC at 1800 UTC 26 September 2015, evolving from a tropical wave that originated in the Atlantic (Berg 2016a). Marty steadily intensified as it slowly moved north toward the Mexican coast, reaching a peak intensity of $70 \mathrm{kt}$ at 1800 UTC 28 September. Sea surface temperatures of near $30^{\circ} \mathrm{C}$ supported the intensification during this time period. However, as the storm moved north it approached the base of a large upper-tropospheric trough, such that the $200-850-\mathrm{hPa}$ environmental vertical wind shear (VWS) gradually increased from $7 \mathrm{kt}$ at 0000 UTC 27 September 2015 to $24 \mathrm{kt}$ at the time of peak intensity [VWS values as diagnosed by the Statistical Hurricane Intensity Prediction Scheme (SHIPS; DeMaria and Kaplan 1994), based on the National Centers for Environmental Prediction (NCEP) Global forecasting System (GFS) analysis].
After the time of peak intensity, the VWS separated the deep convection from the low-level center and the storm quickly weakened while moving parallel to the Mexican coast. Throughout Marty's brief life cycle, the outflow primarily flowed toward the east and northeast, joining with the large-scale uppertropospheric flow associated with the aforementioned trough.

Potential development of Marty off the Pacific coast of Mexico was noted in the 10-day European Centre for Medium-Range Weather Forecasts (ECMWF) ensemble and deterministic forecasts as early as 16 September. It was not until much later, though, that other global and regional dynamical model forecasts also indicated tropical cyclogenesis and subsequent intensification. On 24 September, the decision was made to forward deploy the WB-57 to Harlingen, Texas, in order to maximize on-station time for two science flights over Marty (which at the time was Invest 93E). The first flight took place during the afternoon of 27 September, when Marty was an intensifying tropical storm. The second flight took place the following day near the time of Marty's peak intensity, with dropsondes deployed over the storm between 1827 and 2018 UTC, coincident with a U.S. Air Force Reserve WC-130J low-level reconnaissance mission. The flight tracks and dropsonde launch locations for both Marty missions are shown in Fig. 2b.

The second flight into Marty, on 28 September, featured two center-crossing legs, each with a sequence of high-density dropsonde deployments. The second center-crossing leg was oriented west-southwest to eastnortheast and occurred between 1957 and 2019 UTC. A total of 31 dropsondes were launched along this leg, with approximately $8-\mathrm{km}$ spacing along most of the leg. This flight leg was oriented approximately in the 

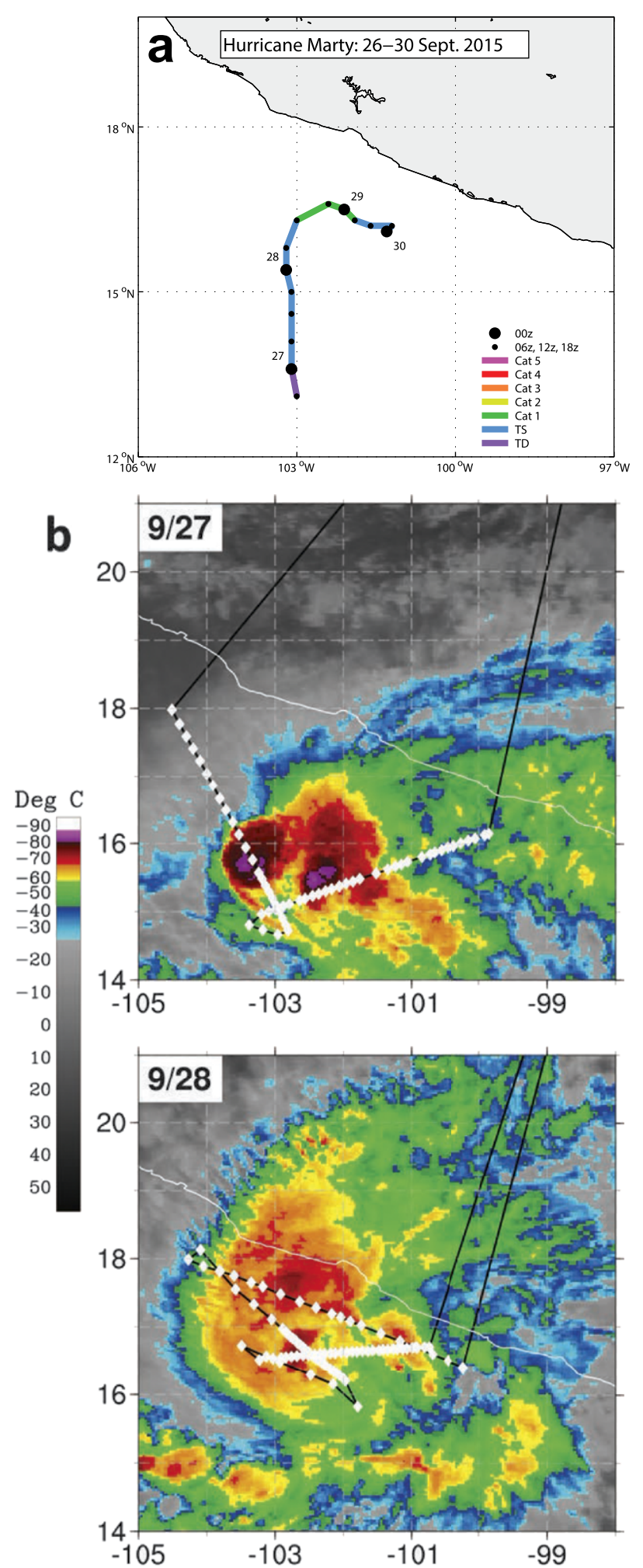

FIG. 2. (a) NHC best track positions and intensities for Hurricane Marty. (b) WB-57 flight track (solid line) and dropsonde launch locations (diamonds) for the two TCl flights over Marty, overlaid on Geostationary Operational Environmental Satellite (GOES) infrared imagery centered on the time the aircraft was over the storm. direction of the VWS vector (as analyzed by SHIPS) and just missed the TC center position (estimated from two Air Force fixes, at 1816 and 1928 UTC) to the south by $6 \mathrm{~km}$. Figure 3 shows cross sections of wind normal to the section and potential temperature $\theta$ (Fig. 3a) and wind parallel to the section and $\theta$ (Fig. $3 \mathrm{~b}$ ), created from the 31 aforementioned dropsondes. The highdensity dropsondes are able to resolve the downshear tilt of the vortex, with the sign change in the normal wind at $400 \mathrm{hPa}$ displaced about $30 \mathrm{~km}$ downshear from the sign change in the normal wind at $800 \mathrm{hPa}$. Little tilt in the normal-wind structure is noted below $800 \mathrm{hPa}$ or above $400 \mathrm{hPa}$. With the aircraft flight level above $80 \mathrm{hPa}$, these cross sections encompass the entire troposphere; the $\theta$ data indicate a distinct tropopause at about $100 \mathrm{hPa}$. Below the tropopause there is a separate layer of enhanced thermal stratification around $125 \mathrm{hPa}$ in the center and on the right side of the cross section. Immediately below this stable layer is a layer of parallel-to-section winds directed from left to right (positive values in Fig. 3b). This wind layer is outflow from convection that is concentrated near the TC center, and the enhanced thermal stratification is likely located just above the top of the cirrus canopy accompanying the outflow, as often seen for similar dropsonde-based wind and temperature profiles taken over TCs in the HS3 experiment (Braun et al. 2016; note that HS3 obtained cloud-top-height information coincident with the dropsonde observations via the Cloud Physics Lidar instrument). Further analysis and modeling is needed to understand the complex upper-tropospheric-lower-stratospheric wind and temperature structure as revealed by the high-density dropsonde deployments performed over Marty, Joaquin, and Patricia. Specific research topics that should be addressed include the cause of the diurnal cycle in the TC cirrus canopy (Dunion et al. 2014) and the relationship between the stratification of the outflow and TC structure and intensity (Emanuel and Rotunno 2011; Emanuel 2012).

Hurricane Joaquin. Joaquin was a late-season Atlantic hurricane that attained a peak intensity of $135 \mathrm{kt}$, which was the most intense Atlantic hurricane since Igor (2010). The NHC best track for Joaquin is shown in Fig. 4a. Joaquin developed from an incipient disturbance of extratropical origin and eventually acquired enough tropical characteristics to be designated a tropical depression by NHC at 0000 UTC 28 September 2015 (Berg 2016b). As Joaquin slowly moved southwestward into the central Bahamas, it rapidly intensified to $120 \mathrm{kt}$ until it reached its southernmost point, at 0000 UTC 2 October. Joaquin 

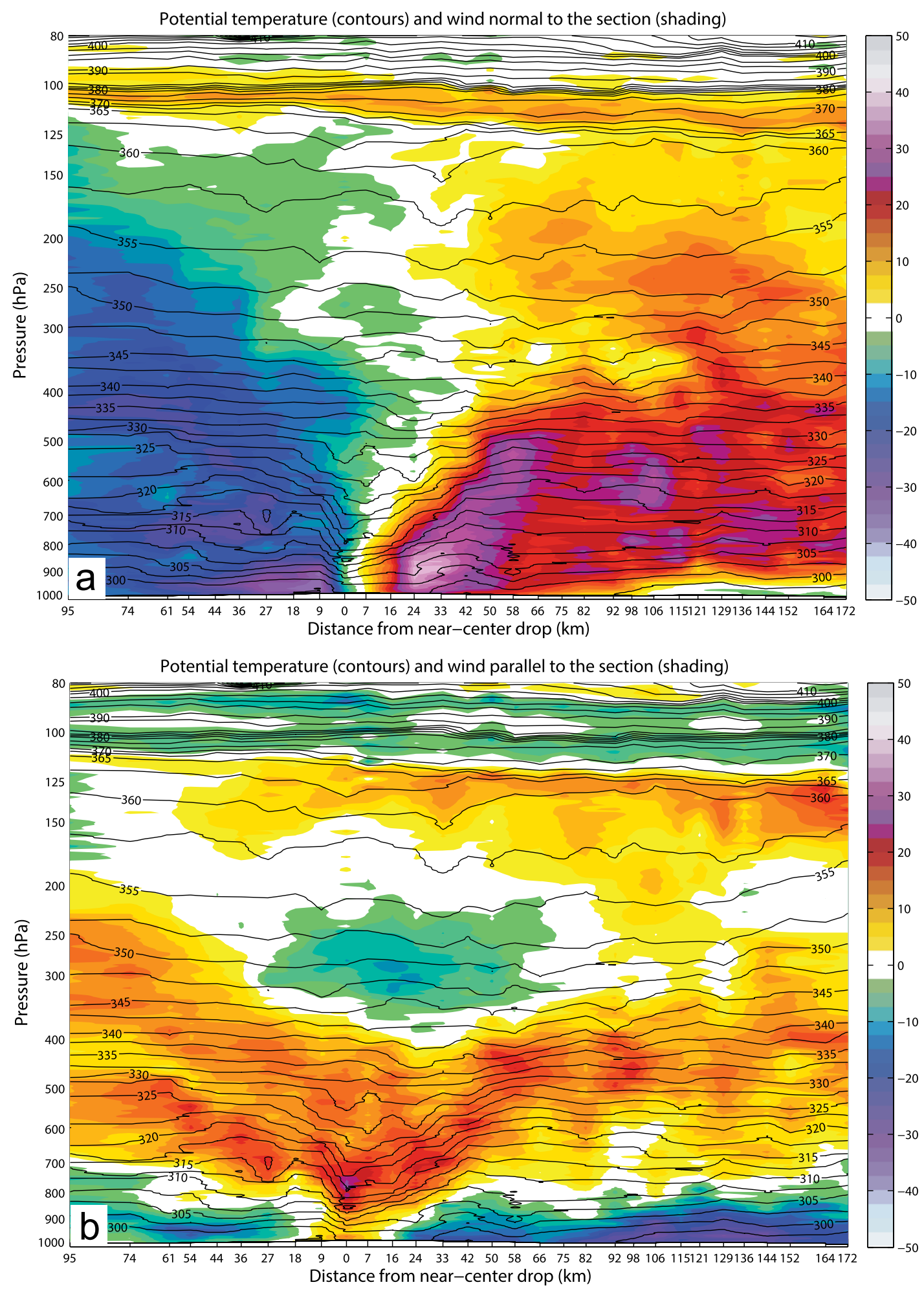

Fig. 3. Vertical cross sections created from 31 dropsondes along the second center-crossing flight leg from the 28 Sep mission over Hurricane Marty. The left edge of the cross sections corresponds to the dropsonde launched at $16.51^{\circ} \mathrm{N}, 103.23^{\circ} \mathrm{W}$ (1957 UTC) and the right edge to the dropsonde launched at $16.70^{\circ} \mathrm{N}, 100.74^{\circ} \mathrm{W}(2018 \mathrm{UTC})$. (a) Wind normal to the section $\left(2.5 \mathrm{~m} \mathrm{~s}^{-1}\right.$ contour interval; positive is into the page) in color shading and potential temperature (2.5-K contour interval) with black contours. (b) As in (a), but for wind parallel to the section (positive is left to right). Tick marks along the abscissa indicate the dropsonde launch locations and are labeled according to the distance from the dropsonde with the lowest pressure observation. 
then turned toward the northeast and accelerated away from the Bahamas as it began to be steered by a deep-layer trough over the eastern United States. The TC reached a peak intensity of $135 \mathrm{kt}$ at 1200 UTC 3 October over an SST of $\sim 30^{\circ} \mathrm{C}$ northeast of the Bahamas. Rapid decay of $60 \mathrm{kt}$ in $36 \mathrm{~h}$ occurred as
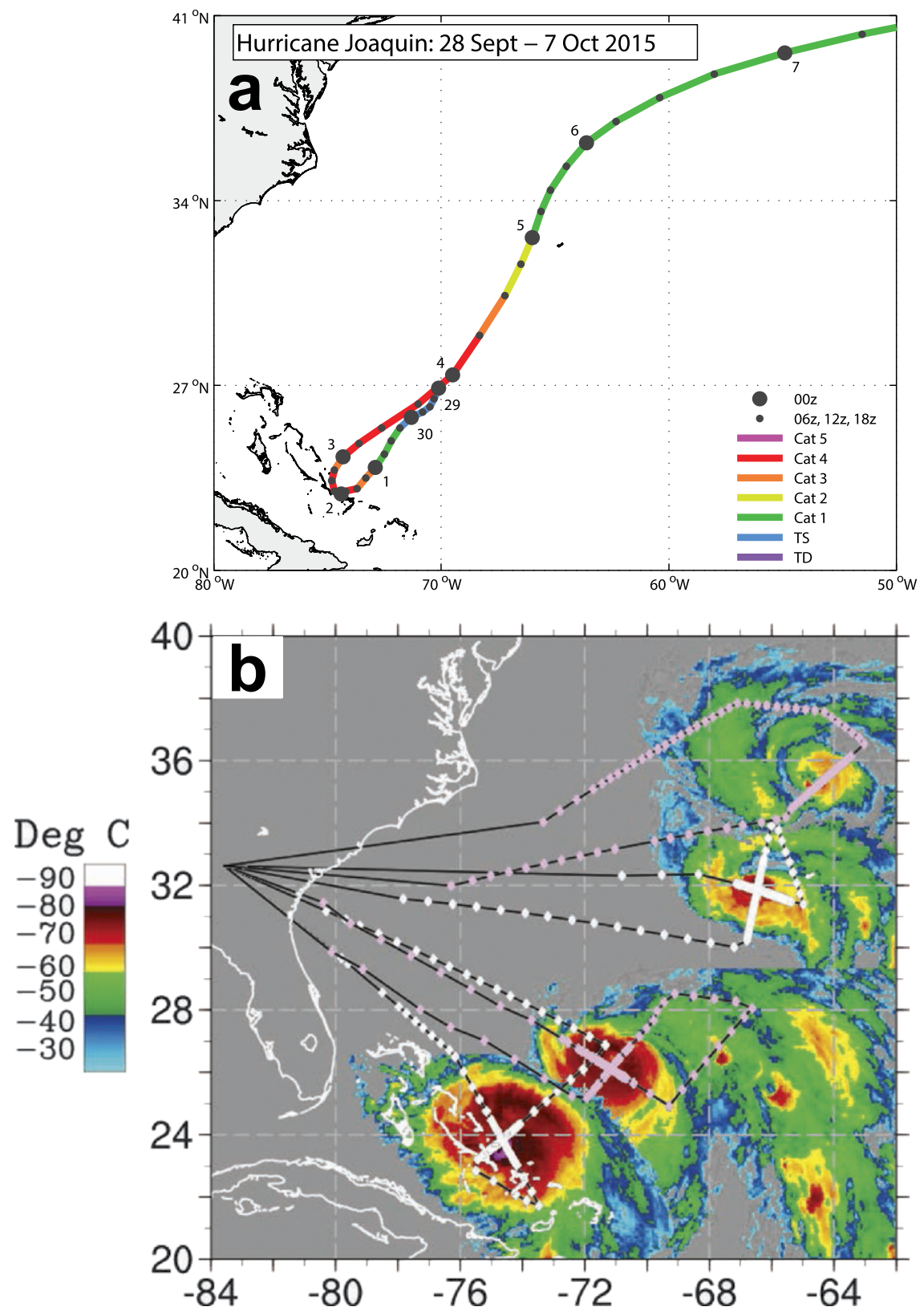

FIG. 4. (a) NHC best track positions and intensities for Hurricane Joaquin. For clarity, best track data before 0000 UTC 29 Sep 2015 are not displayed. (b) WB-57 flight tracks (solid line) and dropsonde launch locations for the four TCI flights over Joaquin, overlaid on a montage of GOES infrared imagery, with each image centered on the time the aircraft was over the storm. Dropsonde launch locations are indicated by white diamonds for the 2 and 4 Oct flights and by pink diamonds for the 3 and 5 Oct flights. The TCl flights followed Joaquin northeast with time.
Joaquin moved northeastward into an environment of lower SSTs and VWS of 25-30 kt (analyzed by SHIPS). However, this rapid decay was interrupted and Joaquin maintained an intensity of $75 \mathrm{kt}$ from 0000 UTC 5 October through 0600 UTC 6 October under more moderate VWS conditions.

After the second Marty mission on 28 September, the TCI team decided to immediately redeploy the WB-57 to Robbins AFB near Macon, Georgia, for a sequence of missions over the developing Joaquin (at that time Tropical Depression 11L). The first Joaquin flight occurred on 2 October, with drops launched between approximately 1600 and 2000 UTC. During this flight Joaquin was a category 3 hurricane over the central Bahamas. Daily flights to Joaquin with similar timings occurred through 5 October, for a total of four flights. The 3 October flight captured Joaquin just after peak intensity, the 4 October flight sampled a rapidly weakening Joaquin approaching Bermuda, and the 5 October flight observed a broad, steady-state TC. Figure 4b shows the flight tracks and dropsonde release locations for the four Joaquin science flights, superimposed on a montage of infrared satellite imagery depicting Joaquin at the times of the four flights.

Azimuthally averaged radius-pressure cross sections of tangential wind and $\theta$ anomalies have been computed based on the dropsondes deployed during the four flights over Hurricane Joaquin (Fig. 5). Dropsonde data are first averaged in $5-\mathrm{hPa}$ 

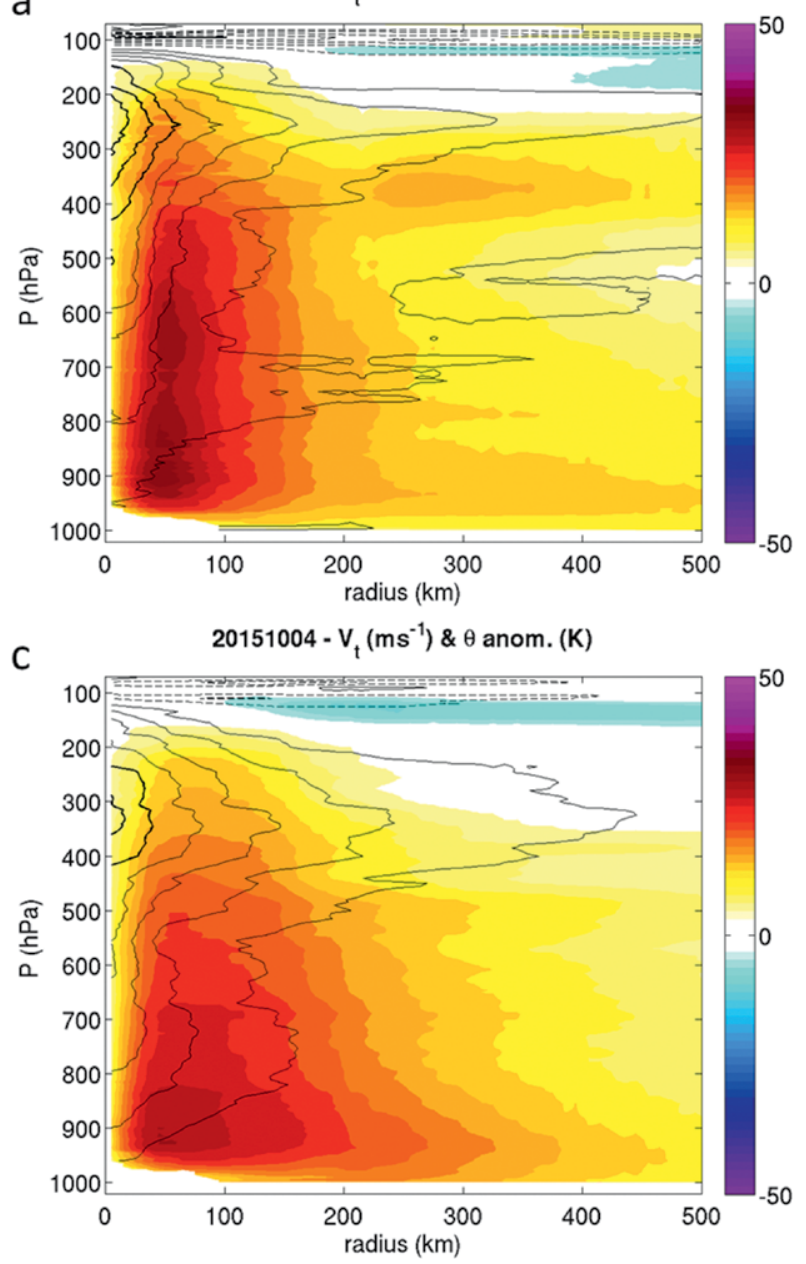

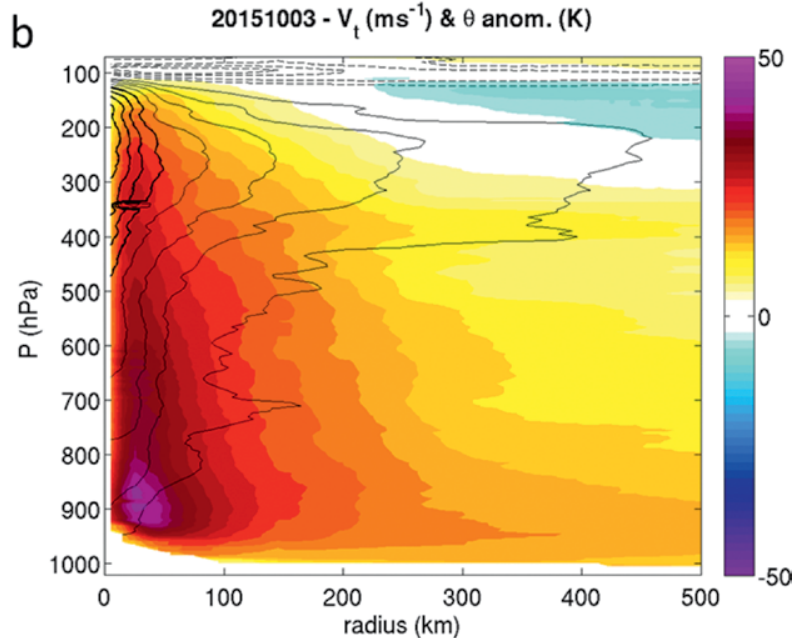

d

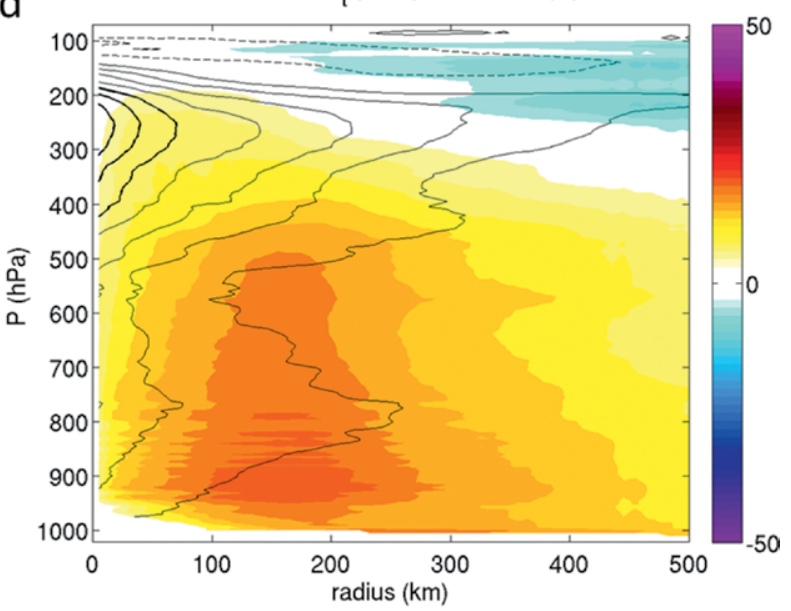

Fig. 5. Azimuthally averaged tangential wind $\left(V_{t}\right.$; shaded every $\left.2.5 \mathrm{~m} \mathrm{~s}^{-1}\right)$ and potential temperature anomaly $(\theta$ anom; contoured every $2 \mathrm{~K}$; solid contours for positive values $<10 \mathrm{~K}$, solid thick contours for positive values $\geq 10 \mathrm{~K}$, dashed contours for negative values) in radius-pressure coordinates for Hurricane Joaquin. Each panel corresponds to a separate TCI mission: (a) 2 Oct, (b) 3 Oct, (c) 4 Oct, and (d) 5 Oct 2015. Potential temperature anomaly is computed with respect to a mean reference profile taken from a $500-1,500-\mathrm{km}$-radius annulus about the TC. Additional data are provided by nearby radiosonde observations. Data are first interpolated in $x-y$ to a $10-\mathrm{km}$ grid, and then averaged azimuthally.

increments in the vertical, interpolated to an $x-y$ grid on each pressure level with $10-\mathrm{km}$ grid spacing, and finally averaged in azimuth. The horizontal interpolation is performed using a natural neighbor technique (Sibson 1981). Anomalies of $\theta$ are computed with respect to the mean horizontally interpolated environment in an annulus of $500-1,500-\mathrm{km}$ radius relative to the TC. Note that the spacing of the dropsonde release points was $10 \mathrm{~km}$ or less in the innercore region and ranged from 20 - to $50-\mathrm{km}$ spacing at locations farther from the TC center for all the Joaquin flights. Since the dropsondes are concentrated at smaller radii, with the majority of the drops occurring within $300 \mathrm{~km}$ of the center of the TC, data at larger radii are supplemented by nearby 0000 and 1200 UTC radiosondes deployed from Bermuda; Jacksonville, Florida; Miami, Florida; Newport, North Carolina; and Nassau, Bahamas. Bermuda also released several special 1800 UTC radiosondes as the island was directly affected by Joaquin. In addition to helping to fill gaps in the missing wind data, these radiosondes are also critical in generating the environmental reference profile from which the $\theta$ anomalies are computed.

The evolution of Hurricane Joaquin was observed by TCI missions in 24 -h increments from approximately 1800 UTC 2 October through 1800 UTC 5 October (Fig. 5). It is clear from these analyses that the vortex was the most intense during the flight on 3 October, with azimuthal-mean 
tangential wind velocities of $\sim 50 \mathrm{~m} \mathrm{~s}^{-1}$ at $900 \mathrm{hPa}$. This value corresponds nicely with the NHC best track that has the official peak intensity of $135 \mathrm{kt}$ occurring at 1200 UTC 3 October, shortly before the 3 October flight. The vortex is the deepest in the vertical on 3 October, and the warm core is the strongest with a magnitude of $>16 \mathrm{~K}$. While there is some evidence of a secondary warm anomaly from 700 to $800 \mathrm{hPa}$, in particular during the flights on 4 and 5 October, the primary warm anomaly remains quite steadily positioned from 350 to $200 \mathrm{hPa}$ for all four flights. By the times of the latter two flights, and particularly the 5 October flight, it is clear that the radius of maximum wind (RMW) has expanded considerably, as is typical of a recurving TC approaching higher latitudes (Mueller et al. 2006; Kossin et al. 2007). A steady weakening trend is also evident as the TC enters an environment associated with greater VWS and lower SSTs.

Figure 6 shows a summary of the HIRAD $10-\mathrm{m}$ wind speed retrievals based on observations obtained during the four Joaquin flights. For the 2 October flight (near the Bahamas) and 4 October flight (near
Bermuda) there were two center crossings, but only data from the second center crossing are shown in full because of the overlapping nature of the flight track. The 3 October flight also has two center crossings, but they are sufficiently displaced such that much of the data from the first crossing can be seen as well as the entire second crossing. This flight, just after the time of peak intensity, shows a highly asymmetric $10-\mathrm{m}$ wind field with the strongest winds localized in the eastern eyewall. In addition to the more asymmetric wind field on 3 October relative to 2 October, the eye size is considerably smaller on 3 October relative to the day prior, consistent with the smaller RMW in the azimuthally averaged tangential winds observed by the dropsondes (see Figs. 5a,b). The 10-m wind speeds on 4 and 5 October are considerably lower than on 2 and 3 October, which is consistent with the azimuthally averaged dropsonde analyses in Figs. $5 \mathrm{c}$ and $5 \mathrm{~d}$.

The HIRAD and dropsonde data both indicate that a considerable change in the structure and intensity of the vortex took place between the 2 and 3 October flights. Joaquin's outflow pattern also evolved substantially during this time period, influenced by the complicated evolution of the upper-level synoptic conditions surrounding the TC. Early in its existence, 29 and 30 September, Joaquin's upper-level outflow was influenced by a large anticyclone centered over the Gulf of Mexico. This potentially aided in creating a persistent southward outflow jet on Joaquin's eastern side, as is evident at 0715 UTC 2 October (Fig. 7a). Joaquin stalled over the Bahamas in weak steering flow between an upper-level low approaching from the northeast and a deep trough approaching from the west. This change in the upperlevel environment resulted in a shift of the outflow from primarily southsoutheastward-directed on 2 October to primarily eastward-directed on 3 October (see Fig. 7b, valid at 1015 UTC 3 October) due to the upper-level low.

FIG. 6. HIRAD I0-m wind speed retrievals for the four TCI missions into Joaquin. 
Additionally, a second, northward-directed outflow channel developed by 2 October and persisted through 3 October, as the aforementioned deep trough impinged on Joaquin from the west. Further research is necessary to elucidate the relationship between the evolution of the upper-tropospheric conditions shown here and the coincident changes in the vortex revealed by the dropsonde and HIRAD data.

As demonstrated by the above analyses, a major achievement of the TCI field campaign was the deployment of high-density dropsondes during TC center overpasses. If these soundings are to be plotted in a storm-relative coordinate system for diagnostic studies, the TC center location must be known to high accuracy. Creasey and Elsberry (2017) have developed a method to calculate the zero-wind-center (ZWC) position from a sequence of dropsondes deployed during these high-altitude TC center overpasses. Their approach is similar to the Willoughby and Chelmow (1982) technique in that it utilizes the intersections of bearings normal to the wind directions across the center to locate the ZWC position. For this application, the bearings are normal to the average wind directions over 1-km layers and are calculated every $200 \mathrm{~m}$ in the vertical from the highly accurate GPS observations. An iterative procedure is used to also account for the storm translation during the dropsonde deployment.

An example of the $200-\mathrm{m}$-interval ZWC positions from three dropsondes deployed during the first center overpass of Hurricane Joaquin on the 4 October flight (near 1800 UTC 4 October) is given in Fig. 8, which shows that the intersection of these bearing lines indicates that the $3.5-\mathrm{km} \mathrm{ZWC}$ is at $31.73^{\circ} \mathrm{N}, 66.52^{\circ} \mathrm{W}$. Using these same three HDSS dropsondes, the ZWC at $9.5 \mathrm{~km}$ is at $31.74^{\circ} \mathrm{N}$, $66.38^{\circ} \mathrm{W}$, which is about $13.3 \mathrm{~km}$ almost due east of the $3.5-\mathrm{km}$ ZWC. Based on the HIRAD $10-\mathrm{m}$ wind speed retrievals, the estimated ZWC at the surface is $31.69^{\circ} \mathrm{N}, 66.58^{\circ} \mathrm{W}$. While this HIRAD position is displaced about $6.7 \mathrm{~km}$ to the south and $5.7 \mathrm{~km}$ to the west of the $3.5-\mathrm{km} \mathrm{ZWC}$, it is uncertain whether these position differences are due to the elevation differences associated with the vortex tilt that is evident in Fig. 8. Just $1 \mathrm{~h}$ later during the second center overpass of Joaquin, the $3.5-\mathrm{km}$ ZWC position is at $31.88^{\circ} \mathrm{N}, 66.44^{\circ} \mathrm{W}$ and the $9.5-\mathrm{km} \mathrm{ZWC}$ is about $19.6 \mathrm{~km}$ to the northeast (not shown). The implication is that during the $1 \mathrm{~h}$ that elapsed since the first center overpass the vortex became more tilted. In summary, the ZWC positions from the two center overpasses on the 4 October flight indicate that the Joaquin vortex tilts from 1- to $10-\mathrm{km}$ elevation and precesses cyclonically with time. Work is in progress

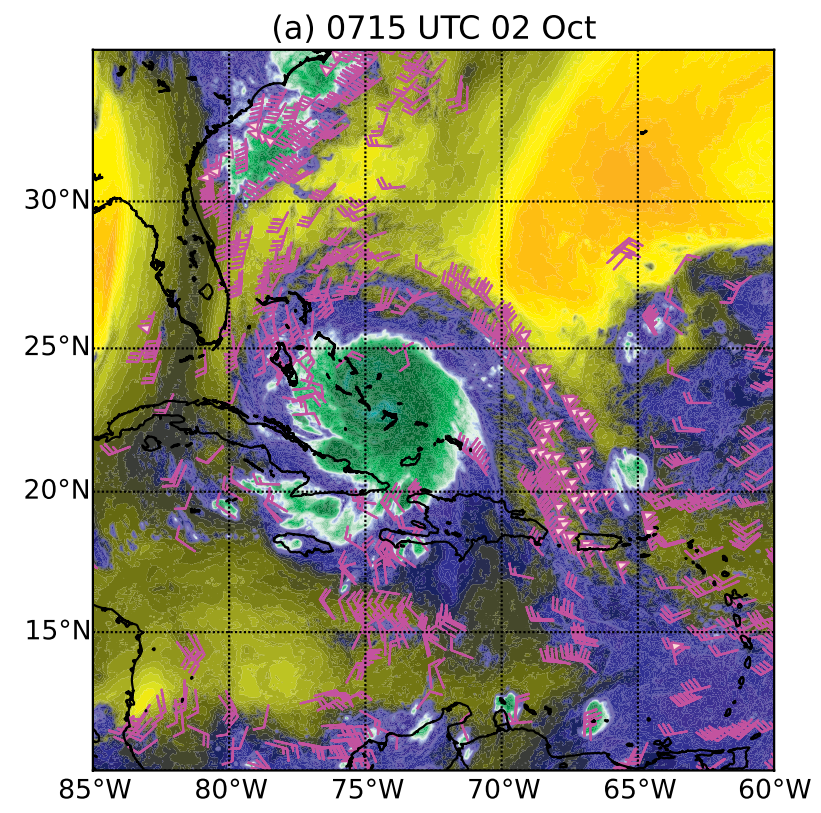

(b) 1015 UTC 03 Oct

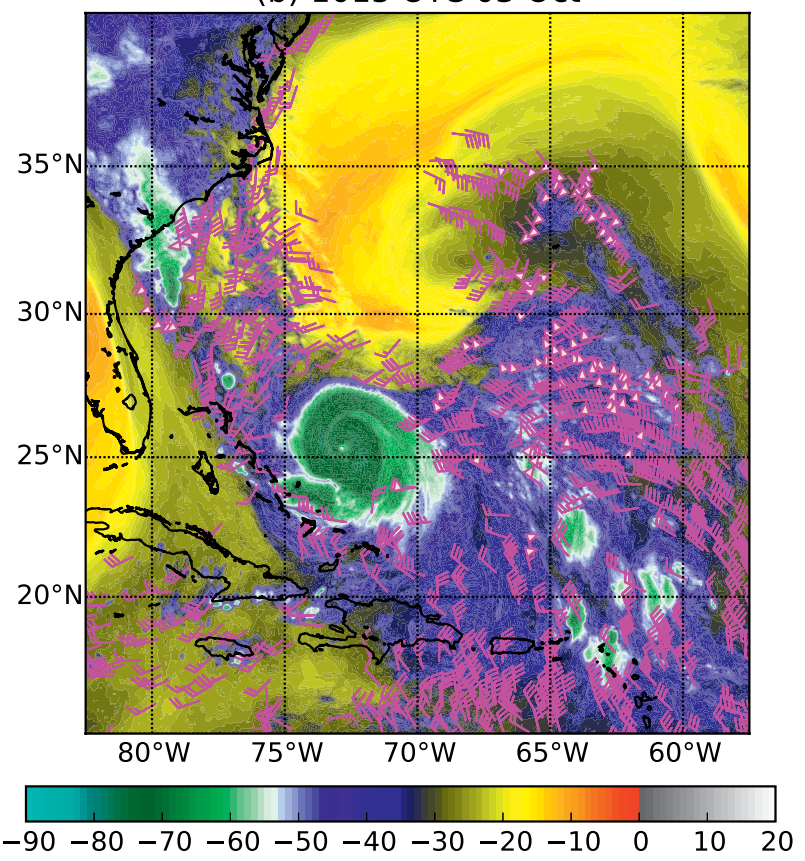

FIG. 7. GOES-I3 water vapor brightness temperature $\left({ }^{\circ} \mathrm{C}\right)$ and atmospheric motion vectors ( $\mathrm{kt}$ ) from $300 \mathrm{hPa}$ and higher for Joaquin at (a) 07 I 5 UTC 2 Oct and (b) 1015 UTC 3 Oct. The outflow structure changes from a predominantly south-southeastward jet in (a) to an eastward jet in (b) as Joaquin interacts with an upper-level low. Additionally, note the second outflow channel to the west ahead of an oncoming trough.

to relate these vortex tilts to the environmental VWS or to an embedded mesoscale vortex.

Hurricane Patricia. Patricia was an eastern North Pacific TC that, over a lifetime of just 4.5 days, formed, 
rapidly intensified into the most intense hurricane on record (185-kt peak intensity), and then rapidly weakened just before landfall in Mexico (Kimberlain et al. 2016; Rogers et al. 2017). The NHC best track for Patricia is shown in Fig. 9a. Patricia was declared a tropical depression at 0600 UTC 20 October and moved west, followed by a more northwestward trajectory into an environment of negligible environmental VWS and SSTs greater than $30^{\circ} \mathrm{C}$. Intensification was steady but not out of the ordinary at first, with the TC reaching $35 \mathrm{kt}$ at 0000 UTC 21 October followed by more rapid intensification reaching $60 \mathrm{kt}$ at 0000 UTC 22 October. Over the next $36 \mathrm{~h}$, Patricia explosively intensified to a remarkable peak of $185 \mathrm{kt}$ at 1200 UTC 23 October. By this time, the TC had turned to the north in response to a trough approaching from the west and would subsequently move northnortheast until landfall at 2300 UTC 23 October. Shear associated with the aforementioned trough increased just before landfall (SHIPS-diagnosed VWS increased from $6 \mathrm{kt}$ at 1800 UTC 23 October to $20 \mathrm{kt}$ at 0000 UTC 24 October), and together with the emergence of a secondary eyewall, promoted rapid weakening of the storm to $130 \mathrm{kt}$ at landfall. Detailed information regarding Patricia's evolution, along with observational data from both TCI and IFEX, can be found in Rogers et al. (2017).

On 17 October the TCI team decided to begin the process of forward deploying the plane to Harlingen, Texas, to be in position for the predicted development of Invest 97E into a TC off the western coast of Mexico. The first of a sequence of four daily flights took place on the afternoon of 20 October, while Patricia was a tropical depression. This flight was a combined mission between TCI and the NOAA-NASA Volcano-Plume Investigation Readiness and Gas-Phase and Aerosol Sulfur (VIRGAS) experiment, and only 13 dropsondes were released due to limited on-station time. The first TCI-only mission into Patricia occurred the next day, 21 October, with a full complement of dropsondes released over the TC from approximately 1900 to 2100 UTC. During this TCI flight there was a coincident NOAA WP-3D low-level reconnaissance mission to observe the steadily intensifying Tropical Storm Patricia. Another TCI flight took place on 22 October, with dropsondes released over Patricia between approximately 1800 and 2000 UTC, again coincident with a NOAA WP-3D low-level reconnaissance mission. This flight observed Patricia as an explosively intensifying category 4 hurricane. The final TCI mission into Patricia took place on 23 October, with dropsondes released between approximately 2000 and 2200 UTC, accompanied again by a NOAA WP-3D low-level reconnaissance mission. This flight captured category 5 Patricia just after its peak intensity, during the rapid weakening phase leading up to landfall. Figure 9b shows the four flight tracks and dropsonde release locations, overlaid on infrared satellite imagery collected while the WB-57 was over the storm.

In contrast to Joaquin, the dropsonde-based azimuthal-mean cross sections through Hurricane Patricia reveal a steady intensification trend throughout the observational period (Figs. 10a-d), with the final mission on 23 October occurring shortly after Patricia attained a peak 
intensity of $185 \mathrm{kt}$. During this final flight, the strongest winds were found quite unexpectedly near $600 \mathrm{hPa}$ as opposed to at the top of the boundary layer $(\sim 900 \mathrm{hPa})$. The RMW was also found to contract significantly with time, ultimately resulting in an extremely compact core. In fact, for the final two flights, interpolation to a $10-\mathrm{km}$ grid is too coarse to adequately resolve Patricia's inner core, where the dropsonde spacing was locally as small as $4 \mathrm{~km}$. However, because of a number of factors, including the evolution of mesoscale storm structure and interpolation of two separate TCI passes through Patricia at different times, interpolation to a finer grid results in some unrealistic artifacts, so only the $10-\mathrm{km}$ analyses are shown. Patricia's warm core anomaly also intensified steadily in time, with a peak anomaly of $21 \mathrm{~K}$ on 23 October. The upperlevel warm core associated with Patricia at hurricane strength (22 and 23 October) was found to be at least $100 \mathrm{hPa}$ higher than that of Joaquin, with the greatest warm anomaly occurring from 150 to $100 \mathrm{hPa}{ }^{1}$ This difference in height of the upper-level warm core may be due, at least in part, to a higher tropopause, colder outflow temperatures, and a higher maximum potential intensity (MPI) associated with Patricia (Emanuel 1986).

For the final Patricia flight on 23 October, there was only time for the aircraft to make one pass over the center before it moved too close to land (see the lower-right panel of Fig. 9b). For this pass, 46 dropsondes were released in a $200-\mathrm{km}$ transect over the TC center, for an
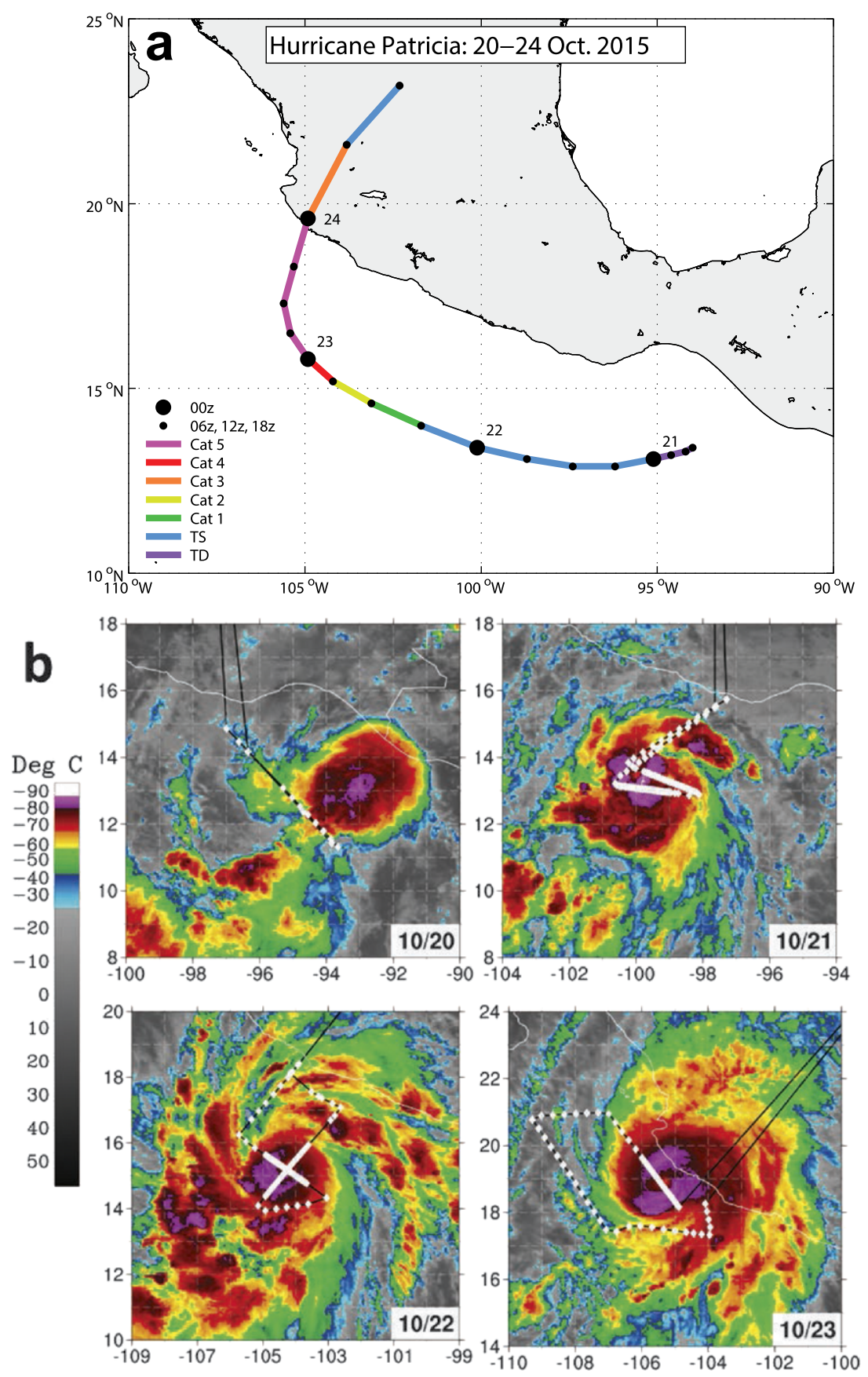

FIG. 9. (a) NHC best track positions and intensities for Hurricane Patricia. (b) WB-57 flight track (solid line) and dropsonde launch locations (diamonds) for the four TCl flights over Patricia, overlaid on GOES infrared imagery centered on the times the aircraft was over the storm.

average spacing of $4.4 \mathrm{~km}$, the highest horizontal resolution utilized for any center crossing during the TCI campaign. The density of the dropsondes, combined with the fact that the transect essentially overflew

\footnotetext{
${ }^{1}$ Note that, in contrast, Rogers et al. (2017) find Patricia's warm core on 23 October to be strongest around $600 \mathrm{hPa}$. However, height of the maximum warm anomaly was found to be quite sensitive to the chosen reference temperature profile and interpolation technique.
} 

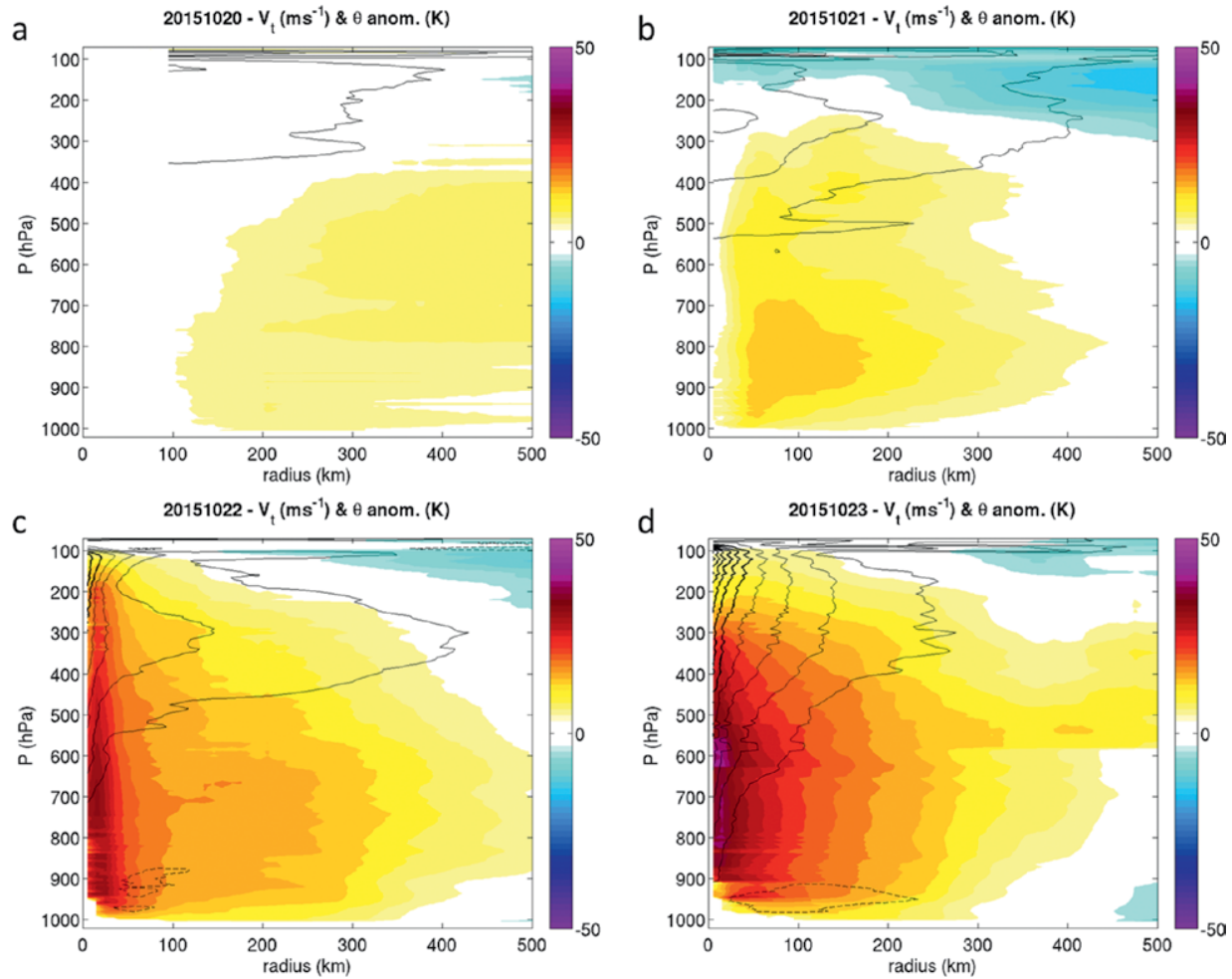

Fig. 10. As in Fig. 5, but for Hurricane Patricia on (a) 20, (b) 21, (c) 22, and (d) 23 Oct 2015.

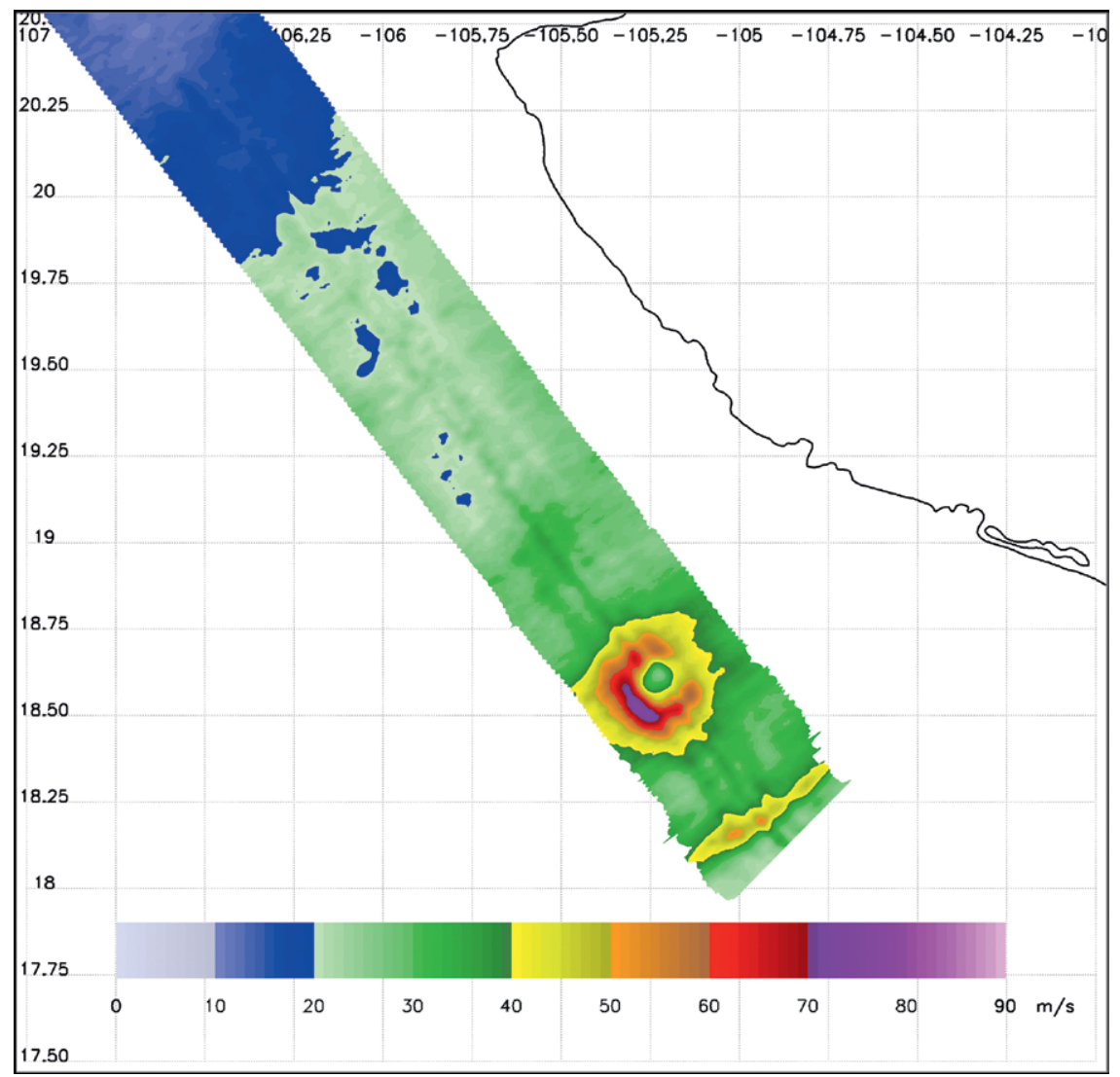

FIG. II. HIRAD I0-m wind speed retrievals for Hurricane Patricia on 23 Oct. the center of a category 5 hurricane (one dropsonde fell almost vertically through the eye) make this a unique and unprecedented dataset.

To provide some context regarding the horizontal structure of the vortex during the 23 October center transect, the HIRAD $10-\mathrm{m}$ wind speed retrievals along the transect are shown in Fig. 11. The eye and primary eyewall are readily apparent. The primary eyewall has a pronounced asymmetry, with winds greater than $70 \mathrm{~m} \mathrm{~s}^{-1}$ on the southwest side but only $40-50 \mathrm{~m} \mathrm{~s}^{-1}$ winds on the northeast side. The eye is very small compared with Joaquin (as shown in Fig. 6), and for such a compact storm HIRAD reveals the complete structure of the inner-core $10-\mathrm{m}$ wind field in a single pass. Near the southeastern edge of the HIRAD swath, there is a secondary wind maximum with $10-\mathrm{m}$ wind speeds locally as high as $50 \mathrm{~m} \mathrm{~s}^{-1}$. This feature is separated from the primary eyewall by a moat of much weaker winds. Microwave satellite imagery and WP-3D lower fuselage radar observations [see Figs. 11 and 12c, respectively, of Rogers et al. (2017)] indicate that the secondary wind maximum observed by HIRAD is accompanied by enhanced convective activity, which encircles most of the inner core. Although it is not clear from the HIRAD observations that a secondary wind maximum exists to the northwest of the inner core, the presence of the secondary wind maximum to the southeast of the inner core together with the 
coincident observations of enhanced convection suggest that a secondary eyewall formed around much of the storm before landfall on 23 October.

Figure 12 shows the horizontal trajectories of a subset of the WB-57 dropsondes from the flight over Patricia on 23 October, overlaid on the horizontal wind speed at $2-\mathrm{km}$ height from the WP-3D Doppler wind analysis [provided by NOAA/Hurricane Research Division (HRD)]. The wind speed shown is a composite from two individual "swath" analyses (Rogers et al. 2012), centered at 1733 and 2033 UTC, respectively. Figure 12 illustrates the high-density sampling capabilities of the HDSS system, as the WB-57 was releasing dropsondes approximately every $4 \mathrm{~km}(20 \mathrm{~s})$, while traversing the eyewall from southeast to northwest. A distinct secondary wind maximum can be seen at $40-50-\mathrm{km}$ radius in the eastern semicircle of Patricia, and this maximum was sampled by both the dropsondes and HIRAD (see Fig. 11, near the southeast edge of the swath). Because of the very small size of Patricia and the relatively coarse $5-\mathrm{km}$ horizontal grid spacing of this Doppler analysis, the structure of the inner wind maximum cannot be fully seen here. ${ }^{2}$ The HDSS dropsondes are able to help fill in this gap in coverage. Note that since the dropsondes move with the horizontal wind, they can drift substantially as they fall from the lower stratosphere to the surface. This is most pronounced in the inner core, where a few dropsondes were advected more than halfway around the eyewall, due to the combination of high wind speeds and a small radius.

Figure 13a shows a vertical cross section of the horizontal wind speed through the center of Patricia, produced using the dropsondes shown in Fig. 12. The dropsondes are spaced irregularly in radius and height, and the radius of a given dropsonde is variable in time. We use the HRD 2-min center positions (based on the WP-3D flight-level data) to calculate the radial location of each dropsonde at each time. To construct a regular cross section, we assign each dropsonde to a fixed radius corresponding to the mean over all heights and bin average the wind speed of each dropsonde every $100 \mathrm{~m}$. Consistent with Figs. 11 and 12 , a secondary wind maximum can be seen in the southeast side of the cross section from 40 - to $50-\mathrm{km}$ radius and below $4-\mathrm{km}$ height. The southeast inner eyewall exhibits an unusual structure, with both the expected boundary layer wind speed maximum and a stronger maximum at about $6 \mathrm{~km}$. This midlevel

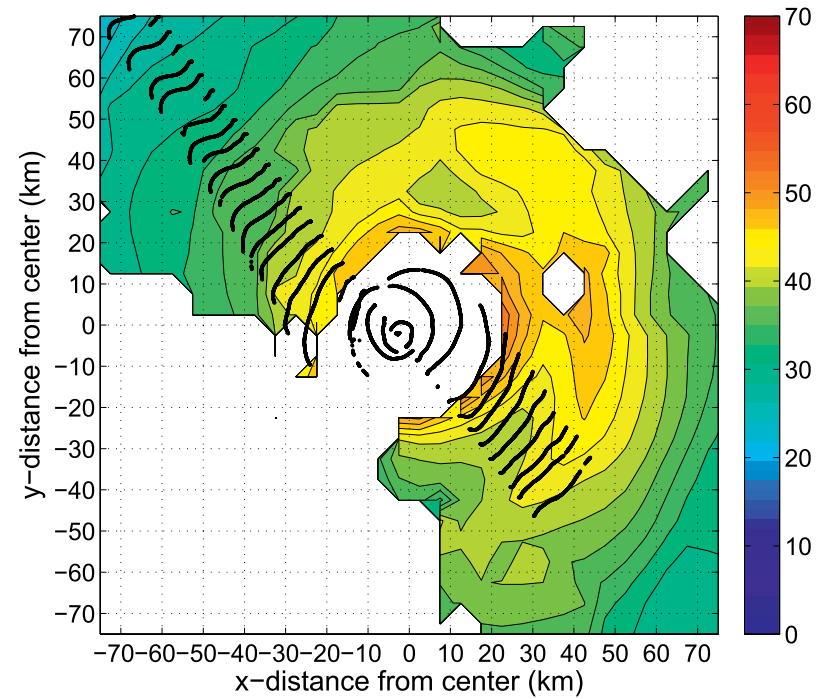

FIG. I2. Composite horizontal wind speed (contoured every $2 \mathrm{~m} \mathrm{~s}^{-1}$ ) at 2-km height for Hurricane Patricia, from WP-3D Doppler analyses from 1733 and 2033 UTC 23 Oct 20I5, and horizontal trajectories of HDSS dropsondes released by the WB-57. The WB-57 flew from southeast to northwest, and the first and last sondes shown were released at 1956:43 and 2009:05 UTC, respectively. The horizontal grid spacing of the Doppler analyses is $5 \mathrm{~km}$, and the analysis data are provided by NOAA/HRD.

maximum is not an artifact of a single dropsonde, as local maxima at about the same height can be seen in at least seven other dropsondes. Unfortunately, several dropsondes released into the northwest eyewall largely failed, precluding analysis. Additionally, it is unclear from the dropsondes alone whether the structure seen in the southeast eyewall is robust, given the complications induced by dropsonde drift and limited sampling of the extremely compact inner core.

To further investigate the eyewall structure, we compared the dropsonde analysis to the Doppler wind analysis from 2033 UTC, about 30 min after the WB-57 overflew the eye. Note that this analysis is obtained using the two-dimensional "profile" method described in Rogers et al. (2012) and has along-track (i.e., radial) and vertical grid spacings of 1.5 and $0.15 \mathrm{~km}$, respectively (Fig. 13b). Note that the WP-3D also flew from southeast to northwest, and so the orientations of the cross sections in Fig. 13 are nearly identical. It can be seen that the overall structure of the inner-core wind field is approximately the same in the Doppler and dropsonde analyses: an inner wind maximum at about $10-\mathrm{km}$ radius, and a

\footnotetext{
${ }^{2}$ Note that Rogers et al. (2017) present an analysis with 1.5-km grid spacing (their Fig. 14) that is able to resolve more of the inner-core wind field, although gaps remain within the eye and southwest eyewall.
} 
Sonde Wind Speed (m/s), Patricia 102315, $\max =82.4$

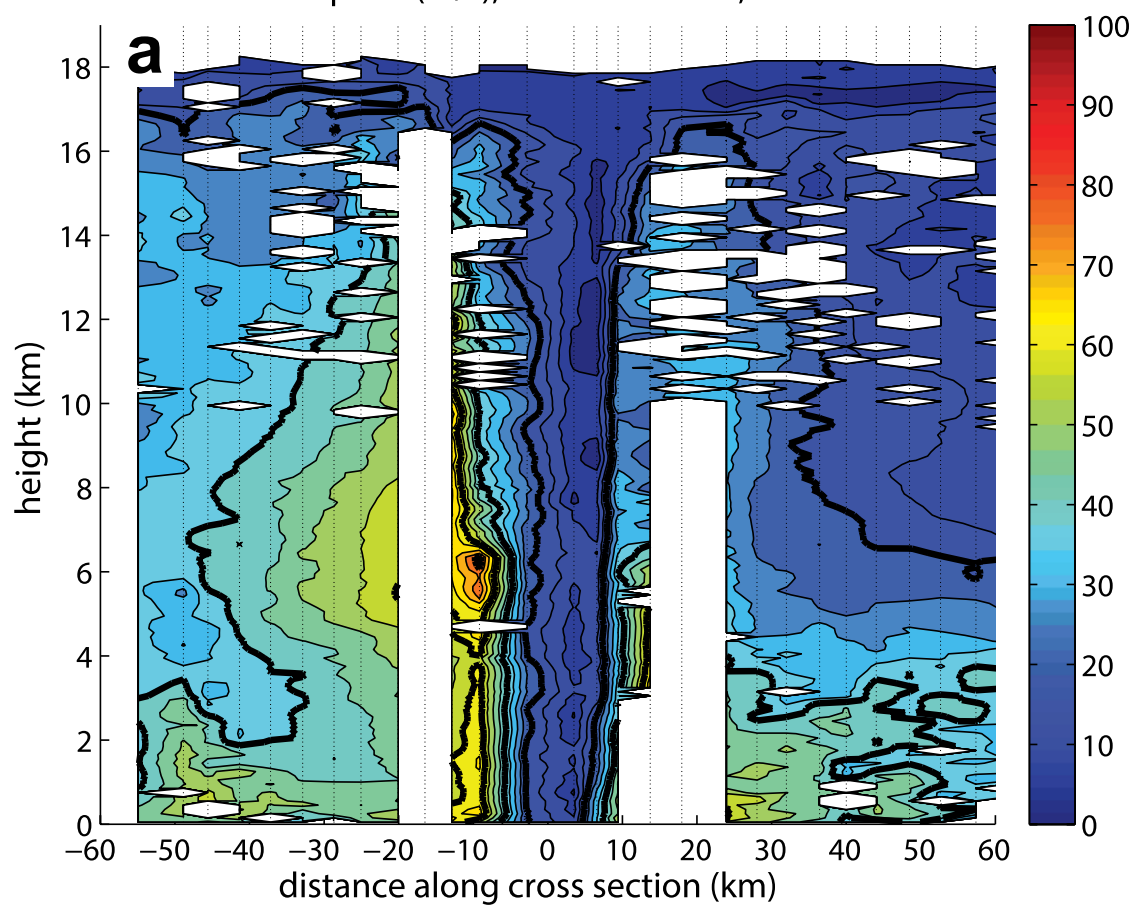

P3 Doppler Wind Speed (m/s), Patricia 102315, $\max =78.9$

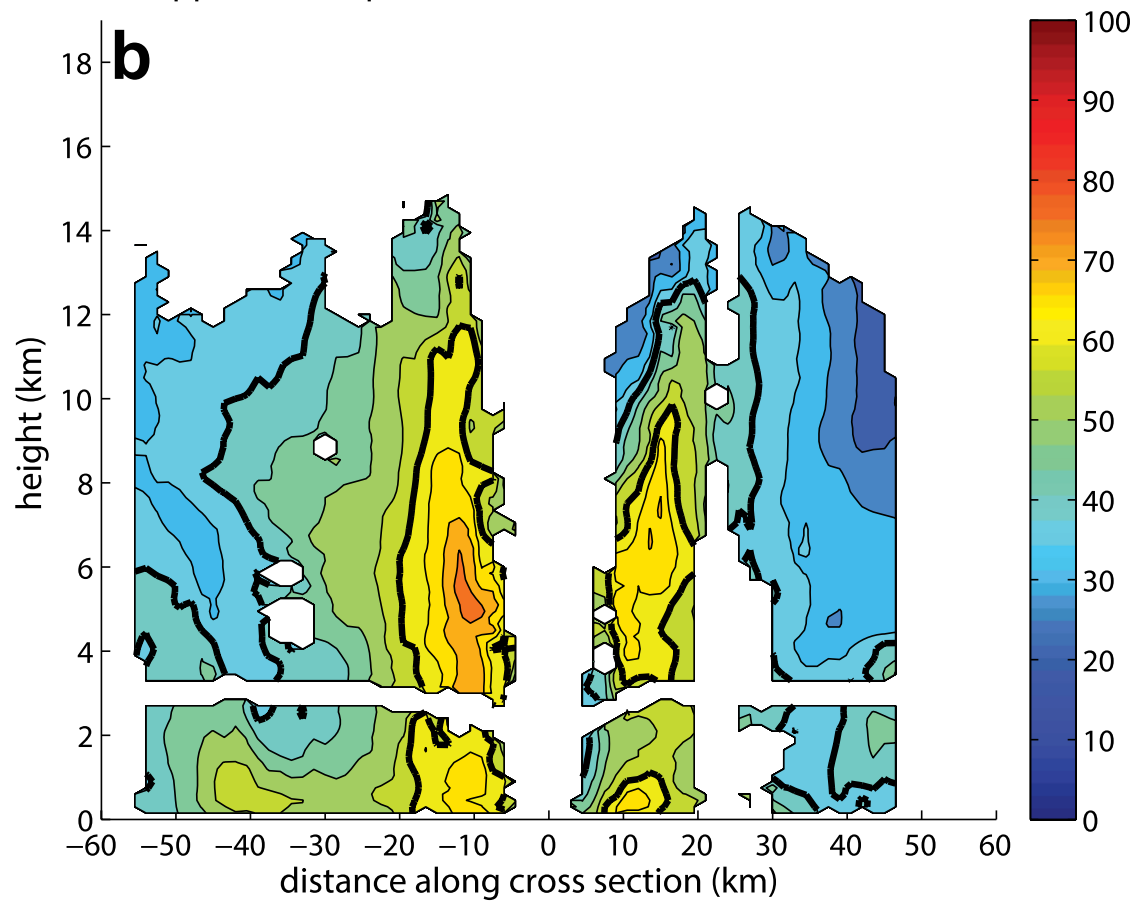

FIG. 13. Distance-height cross sections of horizontal wind speed in Hurricane Patricia on 23 Oct, obtained from (a) WB-57 HDSS dropsondes and (b) WP-3D Doppler analysis. The mean radial location of each of the 27 dropsondes used in (a) is indicated by the vertical dotted lines, and these are the same sondes shown in Fig. 12. The data in (b) are from a single analysis centered at 2033 UTC, and the horizontal and vertical grid spacing is 1.5 and $0.15 \mathrm{~km}$, respectively. Both (a) and (b) use contour intervals of $5 \mathrm{~m} \mathrm{~s}^{-1}$, with every $20 \mathrm{~m} \mathrm{~s}^{-1}$ thickened. White regions denote missing data. The axes of the panels are identical, and the azimuthal orientations of the cross sections are essentially the same, going from southeast (negative) to northwest (positive) through the low-level center of Patricia. shallow outer maximum at $40-50-\mathrm{km}$ radius, more pronounced to the southeast. The midlevel absolute maximum in the inner eyewall is also clearly evident in the Doppler analysis [also see Fig. 16c of Rogers et al. (2017)], and it can be seen that this anomalous structure is additionally present in the northwest eyewall. Although atypical, this midlevel maximum has been seen in a few other intense and/or small TCs and is hypothesized to be a manifestation of unbalanced flow (Stern et al. 2014). We are continuing to investigate the dynamics of this phenomenon.

Figure 14 illustrates the capability of the HDSS dropsondes to resolve finescale structures using data from the high-density inner-core transect of Patricia on 23 October. The release locations of the dropsondes from this transect are shown in Fig. 14a, overlaid on an infrared brightness temperature image from 2000 UTC 23 October. Figure $14 \mathrm{~b}$ shows a radiusheight cross section of $\theta$ created from these dropsondes. The dropsonde data were interpolated to 100 -m vertical levels following Molinari and Vollaro (2010) and plotted in radial coordinates relative to the storm center, defined as the TCI dropsonde deployment location nearest the storm track interpolated between two NOAA P-3 center fixes at 1733 and 2033 UTC. Wherever possible, linear interpolation was performed across missing values in the radial direction. 

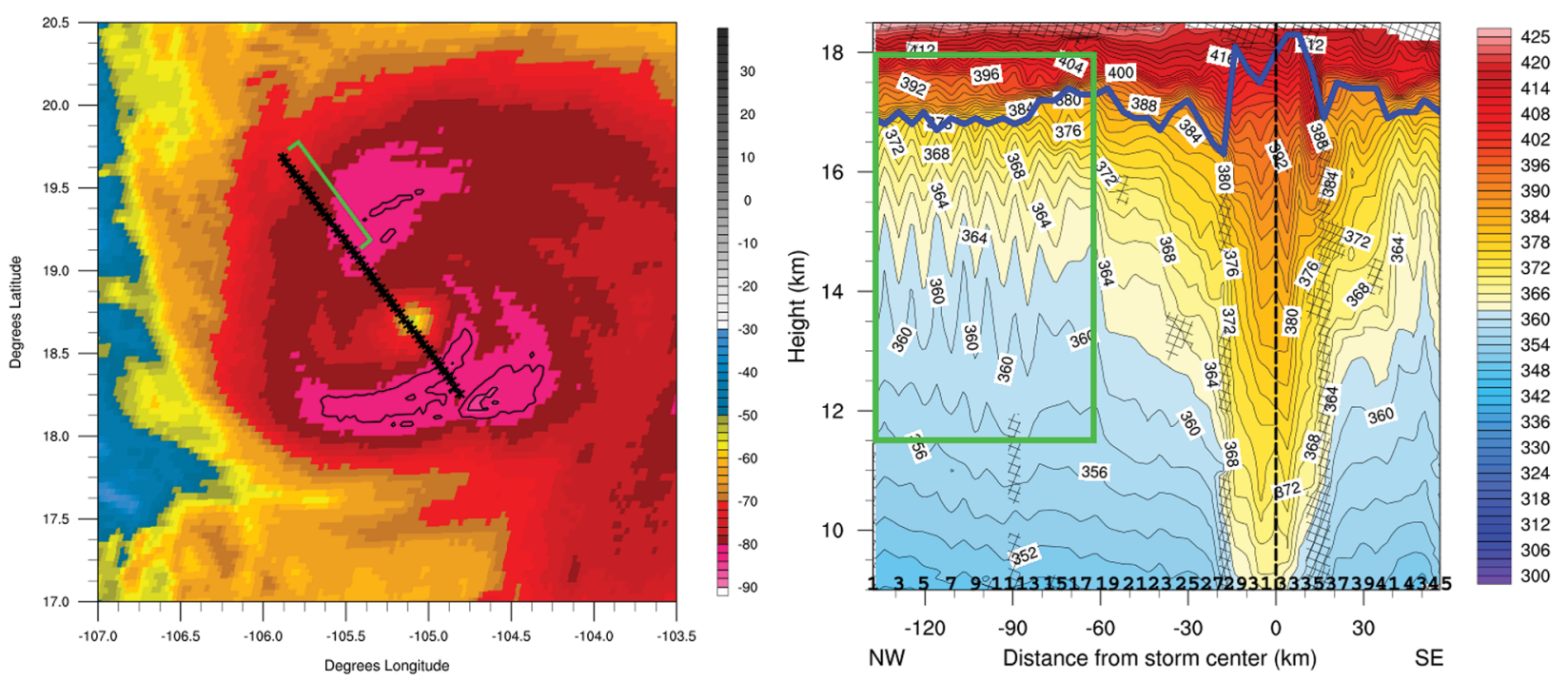

Fig. 14. (left) Infrared brightness temperature image of Hurricane Patricia at 2000 UTC 23 Oct 2016, with parallax-corrected dropsonde deployment locations indicated by black stars. Black contours delineate the coldest brightness temperatures, with a contour interval of $2^{\circ} \mathrm{C}$ starting at $-82^{\circ} \mathrm{C}$. (right) Radial-vertical cross section of potential temperature $(K)$ through the inner core of Hurricane Patricia observed between 1957 and 2012 UTC 23 Oct 2015. The blue line indicates the height of the cold-point tropopause and the dashed vertical black line marks the storm center. Numbers along the bottom of the cross section show dropsonde deployment locations, with "I" corresponding to the westernmost sonde. Letters at the bottom corners of the plot indicate compass directions. Missing values are marked by hatching; where possible, these were filled by linear interpolation in the radial direction. A wavelike disturbance, delineated by the green box in the right panel, falls within a region of the storm indicated by the green bracket in the left panel.

This analysis does not account for dropsonde drift, but that effect is small above $9 \mathrm{~km}$.

A distinct wavelike disturbance exists about 60-130 km northwest of the storm center (Fig. 14b), which might represent inertia-gravity waves. These waves exhibit a nearly constant horizontal wavelength of about $10 \mathrm{~km}$, extend vertically from about $12 \mathrm{~km}$ to the tropopause, and reach maximum amplitude near $14 \mathrm{~km}$. The peak displacements of the isentropes are nearly horizontal, suggesting that the waves have minimal vertical propagation. The waves could potentially be ducted in the outflow layer, similar to what was seen in thunderstorm anvils by Fovell et al. (2006). Knox et al. (2010) described bands in the upper troposphere of a hurricane with a similar horizontal wavelength, but no vertical structure could be identified in their study. To our knowledge this is the first time such features have been resolved by dropsondes in a hurricane.

As discussed in Rogers et al. (2017), real-time intensity predictions from operational dynamical (and statistical) models severely underpredicted Patricia's phenomenal rate of intensification. It is important to understand why this occurred, necessitating investigation into deficiencies in the dynamical models and their initial conditions. Toward this end, we quantify the impact of the various observing systems on model initial conditions for Hurricane Patricia. The Hurricane Weather Research and Forecasting Model (HWRF; Tallapragada et al. 2016) is used in this demonstration with horizontal grid spacing of $0.135^{\circ}, 0.045^{\circ}$, and $0.015^{\circ}$ (approximately 18,6 , and $2 \mathrm{~km}$, respectively) for the outermost, intermediate, and innermost nested grid domains.

A newly developed Gridpoint Statistical Interpolation (GSI), continuously cycled, dual-resolution, hybrid ensemble Kalman filter-variational (EnKFVar) data assimilation (DA) analysis system for HWRF is used in this demonstration. A detailed description of the system is included in Lu et al. (2017) and Lu and Wang (2017, manuscript submitted to Mon. Wea. Rev.). Briefly, the ensemble covariance provided by the HWRF EnKF is used to estimate the flow-dependent background error covariance and is ingested during the GSI variational minimization using the extended control variable method (e.g., Wang et al. 2008; Wang 2010; Wang et al. 2013). To minimize computational cost, a dual-resolution DA configuration is used, in which the $2-\mathrm{km}$ innermost grid ingests the ensemble covariance from the $6-\mathrm{km}$ intermediate grid. A new, prescribed moving nest strategy is adopted to enable continuous DA and 
forecast cycling for ensemble-based DA methods. Following the operational HWRF, DA is only performed on the 2 - and $6-\mathrm{km}$ grids. The outermost domain is updated using the GFS analysis.

Several experiments were conducted to investigate the impact of assimilating the dropsonde data collected by the TCI and IFEX field campaigns on the analysis of Hurricane Patricia. The continuously cycling HWRF hybrid DA system was started at 1800 UTC 20 October, when Patricia was at its incipient stage, and ended at 1200 UTC 24 October, when Patricia weakened to a tropical depression over land. In these experiments, observations from the National Weather Service (NWS) data stream that are used by operational HWRF are assimilated for both the 6 - and $2-\mathrm{km}$ domains. Here we focus only on assimilating the TCI and IFEX data around the time of the third TCI mission, such that all experiments use the same first guess forecast, valid at 1800 UTC 22 October, from the continuously cycled hybrid DA system as their background. The analyses valid at 1800 UTC 22 October are evaluated.

The "Back" experiment utilized no DA at 1800 UTC 22 October and therefore the background state valid at this time is used to initialize the subsequent forecast. "Base" denotes the baseline experiment in which observations from the NWS data stream are assimilated. "TCI" denotes the experiment that assimilated the HDSS dropsonde observations from the TCI field campaign. For comparison, another
a)HRDradar@1km 18Z22

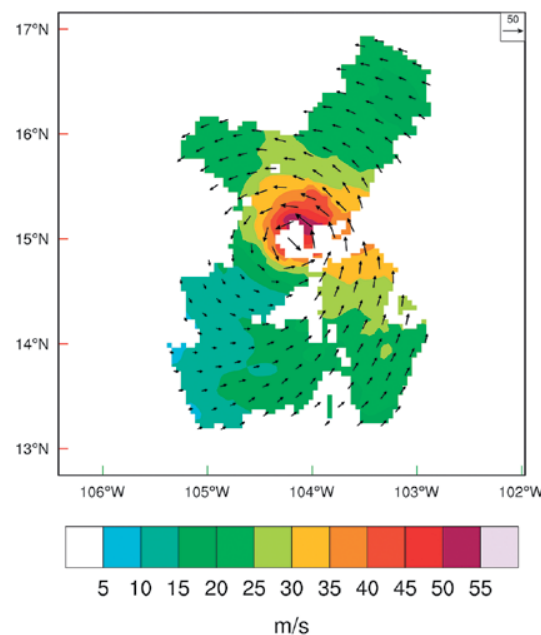

b) Back@1km 18Z22
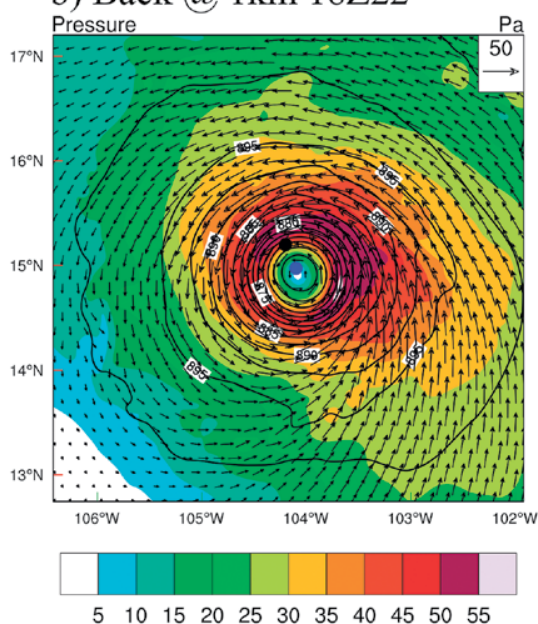

$\mathrm{m} / \mathrm{s}$ c) Base @ 1 km $18 Z 22$

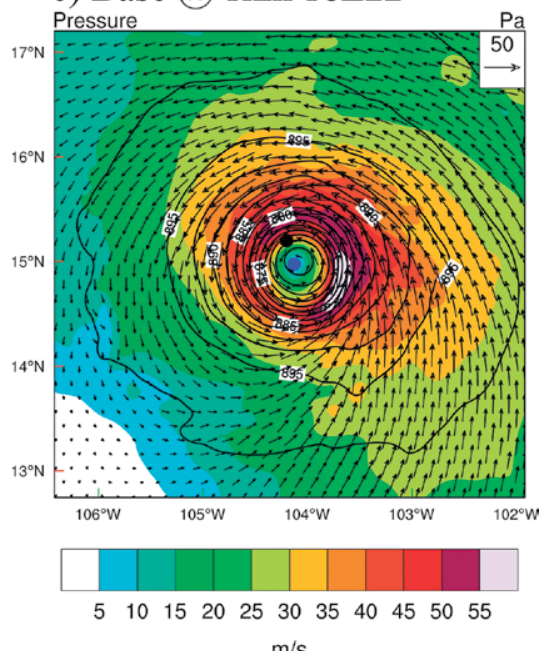

d) TCI@1km $18 \mathrm{Z} 22$

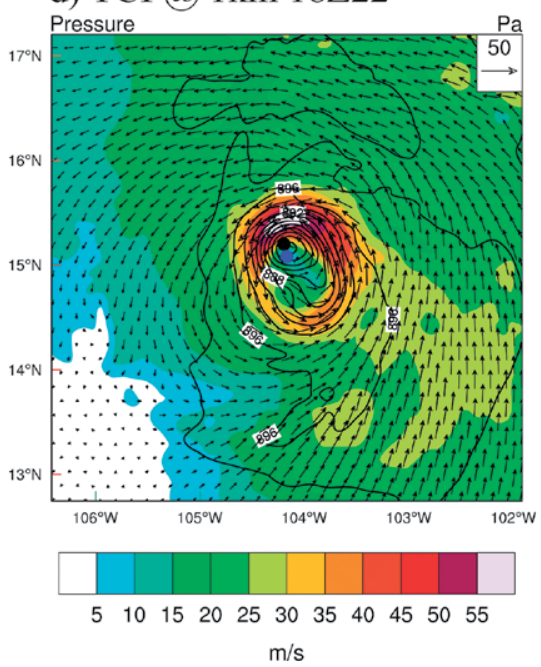

e) TDR@1km $18 Z 22$
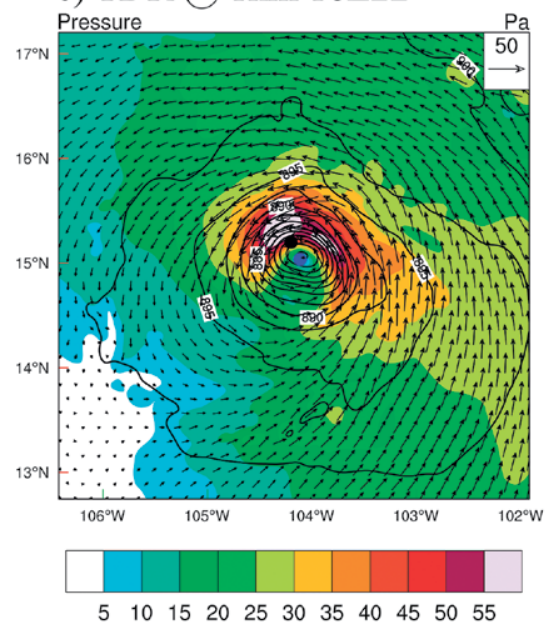

$\mathrm{m} / \mathrm{s}$

FIG. 15. Horizontal wind (shaded and vectors) and pressure (black contours) analyses at I-km height for (a) HRD radar composite, (b) Back, (c) Base, (d) TCI, and (e) TDR experiments valid at 1800 UTC 22 Oct 2015 for Hurricane Patricia. The blue and black dots denote the analyzed storm center and the best track position, respectively. 
experiment "TDR" was conducted by assimilating the radial velocity observations from the tail Doppler radar on board the NOAA WP-3D.

Figure 15 shows the horizontal wind analysis at $1-\mathrm{km}$ height valid at 1800 UTC 22 October from all the aforementioned experiments. The HRD radar composite is used as verification (Fig. 15a). Patricia, as represented by Back (Fig. 15b) without assimilating any data, is much larger than in reality. The wind maximum in Back is in the southeast quadrant rather than the northern semicircle as observed. Base (Fig. 15c) shows nearly no correction of the low-level inner-core structure relative to Back. In contrast, the assimilation of TCI dropsonde data (Fig. 15d) significantly reduces the size of the storm and shifts the wind maximum to the north, consistent with the independent verification from the HRD radar composite. The TCI wind analysis shows an even tighter storm than TDR (Fig. 15e), with the winds in the southwest quadrant more consistent with the verifying radar composite. In summary, assimilating TCI dropsonde data effectively confines the inner core of Patricia to a realistic size, in contrast to the much larger vortex seen in the first guess (Back) or without assimilating inner-core data (Base). Studies of the impact of various sources of data on other aspects of the analysis and on track, structure, and intensity forecasts of Patricia are ongoing, including studies using the Navy's operational tropical cyclone

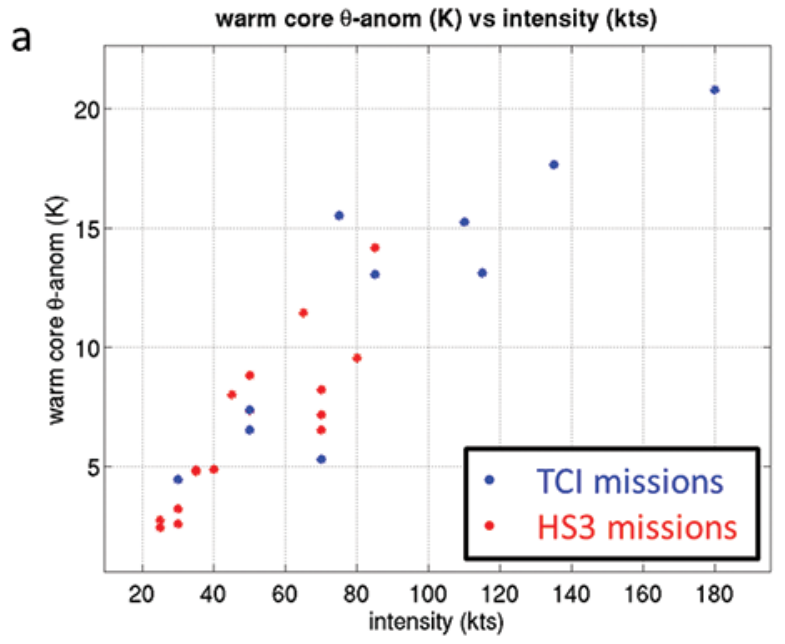

version of the Coupled Ocean-Atmosphere Mesoscale Prediction System (COAMPS-TC; Doyle et al. 2014).

SUMMARY AND OUTLOOK. In the 2015 ONR TCI field campaign, TC outflow and its relationship to intensity change and TC structure were investigated using dropsondes deployed from HDSS and remotely sensed observations from HIRAD, both on board the high-altitude NASA WB-57 research aircraft. Hurricane Joaquin in the Atlantic and Hurricanes Marty and Patricia in the eastern North Pacific were intensively observed, with nearly 800 dropsondes yielding atmospheric profiles from the lower stratosphere to the surface at high horizontal and vertical resolution, along with HIRAD measurements of surface winds in a 50-km-wide swath with a horizontal resolution of $2 \mathrm{~km}$.

Dropsonde transects with $4-10-\mathrm{km}$ spacing through the inner cores of Hurricanes Marty, Joaquin, and Patricia reveal finescale structures in the wind and thermodynamic fields. For Marty, dropsondes resolve the tilt of the TC vortex and capture strong gradients in wind and $\theta$ at the tropopause and the top of the TC outflow layer. In the flights over Joaquin, systematic measurements of the TC outflow layer were made at high spatial resolution for the first time for a major hurricane, highlighting the complex interaction of Joaquin's outflow with multiple synoptic-scale features associated with the

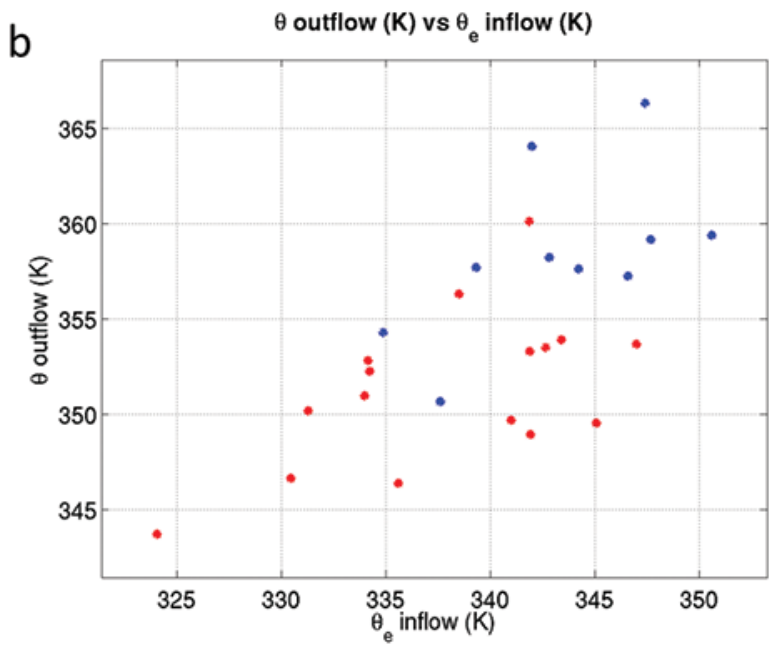

FIG. 16. Scatterplots comparing (a) the magnitude of the maximum $\theta$ anomaly associated with the warm core (K) to present storm intensity (kt) and (b) $\theta$ of the level of strongest $0-500-\mathrm{km}$ mean radial outflow to $\theta_{\mathrm{e}}$ of the level of strongest 0-500 km mean radial inflow. Each dot corresponds to a separate TCI (blue) or HS3 (red) mission. From TCI, all Marty, Joaquin, and Patricia flights are included. From HS3, all missions investigating TCs declared by NHC (no invests) with at least one dropsonde pass over the core are included. Intensity is based upon the corresponding NHC best track intensity valid at the time of the temporal median of the dropsonde release sequence. The $\theta$ anomaly is computed with respect to a mean reference profile taken from a 500-I,500-km-radius annulus about the TC. 
TC's unusually unpredictable track and intensity. Enhanced satellite data (e.g., rapid scan atmospheric motion vectors) during Joaquin reveal new aspects of the hurricane outflow-layer structure. In Patricia, high-resolution dropsonde observations capture finescale TC structures such as an elevated wind maximum in the inner core, oscillatory potential temperature features that are consistent with gravity waves, and detailed inner-core structure from the surface to the tropopause. Surface wind speed swaths obtained by HIRAD for the three aforementioned storms characterize the size and asymmetry of the inner-core surface wind field.

The observations taken during TCI provide opportunities to examine tropical cyclone structure and processes in new ways, particularly when utilized in conjunction with observational data from other field campaigns (e.g., Figs. 12, 13). For instance, the capability to measure the inner core of tropical cyclones from the lower stratosphere to the surface can be examined from a more general perspective including both TCI and HS3 measurements. In the combined analysis, all Marty, Joaquin, and Patricia flights are included. From HS3, all missions investigating TCs declared by NHC (no invests) with at least one dropsonde pass over the core are included. In this example, we explore the magnitude of the maximum $\theta$ anomaly associated with the warm core. For each mission, a single value has been assigned for the magnitude of the maximum $\theta$ anomaly associated with the warm core and is plotted as a function of TC intensity (Fig. 16a). Note that there is a strong positive relationship between strength of the warm core and TC intensity, as should be expected for a balanced vortex (Shapiro and Willoughby 1982). Outflow $\theta$, defined as the $\theta$ level associated with the strongest $0-500-\mathrm{km}$ mean radial outflow, is then plotted versus the equivalent potential temperature $\left(\theta_{e}\right)$ level associated with the strongest $0-500-\mathrm{km}$ mean radial inflow (Fig. 16b). Here a fairly robust positive relationship is also observed, which may have implications for potential intensity (Emanuel 1986). We hope to further leverage the combined data from HS3 and TCI, as well as other field experiments, in future studies.

Looking forward, the demands for highresolution TC observations such as those obtained from HDSS dropsondes and HIRAD retrievals during TCI are greater than ever. Numerical models of TCs continue to increase in horizontal and vertical resolution, outstripping our ability to routinely validate such simulations and forecasts. Incorporating high-resolution observations into advanced data assimilation systems is already showing considerable promise (e.g., Fig. 15). High-fidelity observations are also needed to guide emerging theories of TC intensification that involve a complex interplay of processes that take place on a range of spatial scales. In the future, additional high-resolution dropsonde and surface observations, such as those from HDSS and HIRAD, will be necessary to continue to advance numerical model and data assimilation systems, as well as new theories governing TC intensity change.

ACKNOWLEDGMENTS. This research is supported by the Office of Naval Research Program Element (PE) $0601153 \mathrm{~N}$. We thank the crew of the NASA WB-57 for their excellent support, as well as the USAF 53rd WRS as part of the TROPIC program. We acknowledge NCAR Earth Observing Laboratory for their mission support through the EOL Field Catalog and TCI archive, as well as NASA for support and access to the Mission Tools Suite. COAMPS-TC is a registered trademark of the Naval Research Laboratory.

\section{REFERENCES}

Barrett, B. S., E. Sanabia, S. Reynolds, J. Stapleton, and A. Borrego, 2016: Evolution of the upper-tropospheric outflow in Hurricanes Iselle and Julio (2014) in the Navy Global Environmental Model (NAVGEM) analyses and in satellite and dropsonde observations. J. Geophys. Res. Atmos., 121, 13 273-13286, doi:10.1002/2016JD025656.

Bell, M. M., and Coauthors, 2016: ONR Tropical Cyclone Intensity 2015 NASA WB-57 HDSS dropsonde data, version 1.0. UCAR/NCAR Earth Observing Laboratory, accessed 1 May 2016, doi:10.5065 /D6KW5D8M.

Berg, R., 2016a: Tropical cyclone report, Hurricane Marty. National Hurricane Center, National Weather Service, 17 pp. [Available online at www.nhc.noaa .gov/data/tcr/EP172015_Marty.pdf.]

_ 2016b: Tropical cyclone report, Hurricane Joaquin. National Hurricane Center, National Weather Service, $36 \mathrm{pp}$. [Available online at www.nhc.noaa.gov /data/tcr/AL112015_Joaquin.pdf.]

Black, P. G., and Coauthors, 2007: Air-sea exchange in hurricanes: Synthesis of observations from the Coupled Boundary Layer Air-Sea Transfer experiment. Bull. Amer. Meteor. Soc., 88, 357-374, doi:10.1175/BAMS -88-3-357.

—, L. Harrison, M. Beaubien, R. Bluth, R. Woods, A. Penny, R. Smith, and J. Doyle, 2017: High-Definition Sounding System (HDSS) for atmospheric profiling. 
J. Atmos. Oceanic Technol., 34, 777-796, doi:10.1175 /JTECH-D-14-00210.1.

Braun, S. A., P. A. Newman, and G. M. Heymsfield, 2016: NASA's Hurricane and Severe Storm Sentinel (HS3) investigation. Bull. Amer. Meteor. Soc., 97, 2085-2102, doi:10.1175/BAMS-D-15-00186.1.

Cecil, D. J., and S. K. Biswas, 2017: Hurricane Imaging Radiometer (HIRAD) wind speed retrievals and validation using dropsondes. J. Atmos. Ocean. Tech., doi:10.1175/JTECH-D-17-0031.1, in press.

Creasey, R. L., and R. L. Elsberry, 2017: Tropical cyclone center positions from sequences of HDSS sondes deployed along high-altitude overpasses. Wea. Forecasting, 32, 317-325, doi:10.1175/WAF-D -16-0096.1.

D'Asaro, E. A., and Coauthors, 2014: Impact of typhoons on the ocean in the Pacific. Bull. Amer. Meteor. Soc., 95, 1405-1418, doi:10.1175/BAMS-D-12-00104.1.

DeMaria, M., and J. Kaplan, 1994: A Statistical Hurricane Intensity Prediction Scheme (SHIPS) for the Atlantic basin. Wea. Forecasting, 9, 209-220, doi:10.1175/1520 -0434(1994)009<0209:ASHIPS>2.0.CO;2.

Doyle, J. D., and Coauthors, 2014: Tropical cyclone prediction using COAMPS-TC. Oceanography, 27, 104-115, doi:10.5670/oceanog.2014.72.

Dunion, J. P., C. D. Thorncroft, and C. S. Velden, 2014: The tropical cyclone diurnal cycle of mature hurricanes. Mon. Wea. Rev., 142, 3900-3919, doi:10.1175 /MWR-D-13-00191.1.

Elsberry, R. L., and P. A. Harr, 2008: Tropical Cyclone Structure (TCS08) field experiment science basis, observational platforms, and strategy. Asia-Pac. J. Atmospheric Sci., 44, 209-231.

Emanuel, K. A., 1986: An air-sea interaction theory for tropical cyclones. Part I: Steady-state maintenance. J. Atmos. Sci., 43, 585-605, doi:10.1175/1520 -0469(1986)043<0585:AASITF>2.0.CO;2.

—, 2012: Self-stratification of tropical cyclone outflow. Part II: Implications for storm intensification. J. Atmos. Sci., 69, 988-996, doi:10.1175/JAS-D -11-0177.1.

— - and R. Rotunno, 2011: Self-stratification of tropical cyclone outflow. Part I: Implications for storm structure. J. Atmos. Sci., 68, 2236-2249, doi:10.1175 /JAS-D-10-05024.1.

Flatau, M., and D. E. Stevens, 1993: The role of outflowlayer instabilities in tropical cyclone motion. J. Atmos. Sci., 50, 1721-1733, doi:10.1175/1520 $-0469(1993) 050<1721$ :TROOLI $>2.0$. CO;2.

Fovell, R. G., G. L. Mullendore, and S.-H. Kim, 2006: Discrete propagation in numerically simulated nocturnal squall lines. Mon. Wea. Rev., 134, 3735-3752, doi:10.1175/MWR3268.1.
Halverson, J., and Coauthors, 2007: NASA's Tropical Cloud Systems and Processes Experiment. Bull. Amer. Meteor. Soc., 88, 867-882, doi:10.1175/BAMS -88-6-867.

Hock, T. F., and J. L. Franklin, 1999: The NCAR GPS dropwindsonde. Bull. Amer. Meteor. Soc., 80, 407-420, doi:10.1175/1520-0477(1999)080<0407: TNGD >2.0.CO;2.

Holland, G. J., and R. T. Merrill, 1984: On the dynamics of tropical cyclone structural changes. Quart. J. Roy. Meteor. Soc., 110, 723-745, doi:10.1002/qj .49711046510.

Kimberlain, T. B., E. S. Blake, and J. P. Cangialosi, 2016: Tropical cyclone report, Hurricane Patricia. National Hurricane Center, National Weather Service, 32 pp. [Available online at www.nhc.noaa.gov/data/tcr /EP202015_Patricia.pdf.]

Knox, J. A., A. S. Bachmeier, W. M. Carter, J. E. Tarantino, L. C. Paulik, E. N. Wilson, G. S. Bechdol, and M. J. Mays, 2010: Transverse cirrus bands in weather systems: A grand tour of an enduring enigma. Weather, 65, 35-41, doi:10.1002/wea.417.

Komaromi, W. A., and J. D. Doyle, 2017: Tropical cyclone outflow and warm core structure as revealed by HS3 dropsonde data. Mon. Wea. Rev., 145, 1339-1359, doi:10.1175/MWR-D-16-0172.1.

Kossin, J. P., J. A. Knaff, H. I. Berger, D. C. Herndon, T. A. Cram, C. S. Velden, R. J. Murnane, and J. D. Hawkins, 2007: Estimating hurricane wind structure in the absence of aircraft reconnaissance. Wea. Forecasting, 22, 89-101, doi:10.1175/WAF985.1.

Lu, X., and X. Wang, Y. Li, M. Tong, and X. Ma, 2017: GSI-based ensemble-variational hybrid data assimilation for HWRF for hurricane initialization and prediction: Impact of various error covariances for airborne radar observation assimilation. Quart. J. Roy. Meteor. Soc., 143, 223-239, doi:10.1002/qj.2914.

Merrill, R. T., 1988a: Environmental influences on hurricane intensification. J. Atmos. Sci., 45, 1678-1687, doi:10.1175/1520-0469(1988)045<1678:EIOHI >2.0 .CO;2.

- 1988 b: Characteristics of the upper-tropospheric environmental flow around hurricanes. J. Atmos. Sci., 45, 1665-1677, doi:10.1175/1520 -0469(1988)045<1665:COTUTE >2.0.CO;2.

Molinari, J., and D. Vollaro, 1989: External influences on hurricane intensity. Part I: Outflow layer eddy angular momentum fluxes. J. Atmos. Sci., 46, 1093-1105, doi:10.1175/1520-0469(1989)046<1093: EIOHIP $>2.0 . C O ; 2$.

— and — 2010: Distribution of helicity, CAPE, and shear in tropical cyclones. J. Atmos. Sci., 67, 274-284, doi:10.1175/2009JAS3090.1. 
Mueller, K. J., M. DeMaria, J. A. Knaff, J. P. Kossin, and T. H. Vonder Haar, 2006: Objective estimation of tropical cyclone wind structure from infrared satellite data. Wea. Forecasting, 21, 990-1005, doi:10.1175/WAF955.1.

Rappin, E. D., M. C. Morgan, and G. J. Tripoli, 2011: The impact of outflow environment on tropical cyclone intensification and structure. J. Atmos. Sci., 68, 177-194, doi:10.1175/2009JAS2970.1.

Rogers, R., and Coauthors, 2006: The Intensity Forecasting Experiment: A NOAA multiyear field program for improving tropical cyclone intensity forecasts. Bull. Amer. Meteor. Soc., 87, 1523-1537, doi:10.1175/BAMS-87-11-1523.

- S. Lorsolo, P. Reasor, J. Gamache, and F. Marks, 2012: Multiscale analysis of tropical cyclone kinematic structure from airborne Doppler radar composites. Mon. Wea. Rev., 140, 77-99, doi:10.1175 /MWR-D-10-05075.1.

—_, and Coauthors, 2013: NOAA's Hurricane Intensity Forecasting Experiment: A progress report. Bull. Amer. Meteor. Soc., 94, 859-882, doi:10.1175/BAMS -D-12-00089.1.

—, S. Aberson, M. M. Bell, D. J. Cecil, J. D. Doyle, J. Morgerman, L. K. Shay, and C. Velden, 2017: Rewriting the tropical record books: The extraordinary intensification of Hurricane Patricia (2015). Bull. Amer. Meteor. Soc., doi:10.1175/BAMS -D-16-0039.1, in press.

Sanabia, E. R., B. S. Barrett, P. G. Black, S. Chen, and J. A. Cummings, 2013: Real-time upper-ocean temperature observations from aircraft during operational hurricane reconnaissance missions: AXBT Demonstration Project year one results. Wea. Forecasting, 28, 1404-1422, doi:10.1175/WAF-D-12-00107.1.

Shapiro, L. J., and H. E. Willoughby, 1982: The response of balanced hurricanes to local sources of heat and momentum. J. Atmos. Sci., 39, 378-394, doi:10.1175/1520-0469(1982)039<0378:TROBHT $>2.0 . \mathrm{CO} ; 2$.

Sibson, R., 1981: A brief description of natural neighbor interpolation. Interpreting Multivariate Data, V. Barnett, Ed., Chichester, 21-36.

Stern, D. P., J. R. Brisbois, and D. S. Nolan, 2014: An expanded dataset of hurricane eyewall sizes and slopes. J. Atmos. Sci., 71, 2747-2762, doi:10.1175/JAS-D-13-0302.1.
—, G. H. Bryan, and S. D. Aberson, 2016: Extreme low-level updrafts and wind speeds measured by dropsondes in tropical cyclones. Mon. Wea. Rev., 144, 2177-2204, doi:10.1175/MWR-D-15-0313.1.

Tallapragada, V., and Coauthors, 2016: Hurricane Weather Research and Forecasting (HWRF) Model: 2015 scientific documentation. NCAR Tech. Note NCAR/TN-522+STR, 122 pp, doi:10.5065 /D6ZP44B5.

Uccellini, L., 1990: Process contributing to rapid development of extratropical cyclones. Extratropical Cyclones: The Erik Palmen Memorial Volume, C. W. Newton and E. O Holopainen, Eds., Amer. Meteor. Soc., 81-105.

Uhlhorn, E. W., P. G. Black, J. L. Franklin, M. Goodberlet, J. Carswell, and A. S. Goldstein, 2007: Hurricane surface wind measurements from an operational stepped frequency microwave radiometer. Mon. Wea. Rev., 135, 3070-3085, doi:10.1175 /MWR3454.1.

Wang, X., 2010: Incorporating ensemble covariance in the gridpoint statistical interpolation variational minimization: A mathematical framework. Mon. Wea. Rev., 138, 2990-2995, doi:10.1175 /2010MWR3245.1.

— D. M. Barker, C. Snyder, and T. M. Hamill, 2008: A hybrid ETKF-3DVAR data assimilation scheme for the WRF model. Part I: Observing system simulation experiment. Mon. Wea. Rev., 136, 5116-5131, doi:10.1175/2008MWR2444.1.

—, D. Parrish, D. Kleist, and J. Whitaker, 2013: GSI 3DVar-based ensemble-variational hybrid data assimilation for NCEP Global Forecast System: Single resolution experiments. Mon. Wea. Rev., 141, 4098-4117, doi:10.1175/MWR-D-12-00141.1.

Willoughby, H. E., and M. B. Chelmow, 1982: Objective determination of hurricane tracks from aircraft observations. Mon. Wea. Rev., 110, 1298-1305, doi:10.1175/1520-0493(1982)110<1298:ODOHTF $>2.0 . \mathrm{CO} ; 2$.

Zipser, E. J., and Coauthors, 2009: The Saharan air layer and the fate of African easterly waves-NASA's AMMA field study of tropical cyclogenesis. Bull. Amer. Meteor. Soc., 90, 1137-1156, doi:10.1175 /2009BAMS2728.1. 